\title{
Egyptian Funerary Boat Model in the Australian Museum: Dating and Analysis
}

\author{
Stan Florek ${ }^{1} \mathbb{D}$, Heather Bleechmore ${ }^{2}$ iD, Jana Jones ${ }^{3}$, \\ Colin McGregor ${ }^{2}$, Ross Pogson ${ }^{2}$ id, AND Jim SpeCht ${ }^{2}$ iD \\ ${ }^{1}$ Engagement, Exhibitions \& Cultural Connection, \\ Australian Museum, 1 William Street, Sydney NSW 2010, Australia \\ ${ }^{2}$ Australian Museum Research Institute, \\ Australian Museum, 1 William Street, Sydney NSW 2010, Australia \\ ${ }^{3}$ Department of Ancient History, Macquarie University, \\ Balaclava Road, Macquarie Park NSW 2109, Australia
}

\begin{abstract}
The unprovenanced and stylistically unusual wooden boat model (AM E60381) from the Australian Museum collection is examined to assess its identity and age. The analyses of construction method, wood, pigments, and gesso demonstrate the boat's compatibility with ancient Egyptian craftwork. Three species of wood are identified: cedar of Lebanon (Cedrus libani), sycomore fig (Ficus sycomorus), and sidr (Ziziphus spina-christi). Funerary boat models are distinctly associated with the 11th and 12th dynasties (mid-20th to 19th century BC). Yet eight radiocarbon dates obtained from six separate pieces of wood are between 24th and 16th century BC; six cluster at the late 3rd millennium BC. Conspicuous disparity between these dates and expected chronological context is discussed. Stylistically, resembling a divine (sun) barque, the model has no parallels among comparable representations. With combination of iconographic motifs, construction methods and radiocarbon dates, the model is attributed to the period spanning the late Old Kingdom and the early Middle Kingdom.
\end{abstract}

\section{Introduction}

Over the past two centuries, a widespread fascination with Egyptian civilization has resulted in a staggering dispersal of its ancient relics and artefacts around the world (Eldamaty \& Trad, 2002; Stevenson 2019). Many artefacts acquired as souvenirs, "trophies" and collectible curios have only vague, if any, provenance and some are modern replicas or fakes (Fiechter, 2009; Boange, 2012). In some cases, it is difficult to prove their authenticity (Lilyquist, 2003:270). These artefacts constitute a significant body of material evidence, but are often of limited value for historical and cultural studies. In this paper we examine one such unprovenanced artefact, the wooden model of a funerary boat, the authenticity of which has been questioned.

Our aim is to explore and assess the feasibility of meaningful research on artefacts deprived of context and specific provenance. We are mindful that not all individual relics can be usefully studied, but new and some wellestablished analytical techniques increasingly make such research possible. This boat model offers the opportunity for a range of analyses relating to materials (wood, and various organic and non-organic substances), structural complexity and stylistic intricacy in form, colours and symbolic connotations, which are likely to reveal some clues about the boat's origin and its history.

\footnotetext{
Keywords: archaeology; Egypt, funerary boat model; iconography; Middle Kingdom; Old Kingdom; pigments; radiocarbon dating; wood species Corresponding author: Stan Florek Stan.Florek@Australian.Museum

Received: 20 October 2020 Accepted: 13 July 2021 Published: 22 September 2021 (in print and online simultaneously) Publisher: The Australian Museum, Sydney, Australia (a statutory authority of, and principally funded by, the NSW State Government)

Citation: Florek, Stan, Heather Bleechmore, Jana Jones, Colin McGregor, Ross Pogson, and Jim Specht. 2021. Egyptian funerary boat model in the Australian Museum: dating and analysis. Records of the Australian Museum 73(2): 67-85. https://doi.org/10.3853/j.2201-4349.73.2021.1738

Copyright: (c) 2021 Florek, Bleechmore, Jones, McGregor, Pogson, Specht. This is an open access article licensed under a Creative Commons Attribution 4.0 International License (CC BY 4.0), which permits unrestricted use, distribution, and reproduction in any medium, provided the original authors and source are credited. 
Funerary boat objects, such as the one under study, have an explicit ritual purpose which relates directly to Egyptian cultural practices in life and the hereafter. Boats and ships, like the River Nile itself, were omnipresent in daily life, administration, politics and in the elaborate concept of supernatural and divine (Creasman, 2013:154). Their symbolic and metaphorical significance seems to be an inherent part of watercraft; actual boats, their pictorial representations, and models (Rich, 2013). Boats were the most complex timber structures built in ancient Egypt (Dürring, 1995; Creasman, 2005), as exemplified by the Khufu ship (Lipke, 1984). They made their way into Egyptian iconography, associated with both the profane and the sacred (Abubakr \& Mustafa, 1971; Ward, 2000; Creasman \& Doyle, 2015; Arnold, 2015b; Wegner, 2017).

The Australian Museum boat model AM E60381 (Figs 1 and 7, Plate 1), is just over one metre long. Iconographic elements imply it depicts a funeral journey (Australian Museum, 2017:117). Its shallow hull is decorated at both ends with inward looking ram heads. The central figure is a mummy resting on a bier flanked on each side by a pair of squatting mourners. On the flat canopy above is the figure of a reclining "jackal"-Anubis - the most unambiguous symbol - the representation of a deity invariably associated with the dead, mummification, and the afterlife, especially in the pre-Middle Kingdom period. The boat itself may represent an actual watercraft, specific or generic, with elements of a mythological vessel, parallel to the divine (solar) barque and funerary boats known from pictorial and "sculptural" sources (Kemp, 2006:249; Brier \& Hobbs, 2008:56).

This boat has no documented provenance. It was donated to the Museum by Ernest J. Wunderlich, a long-term Trustee of the Australian Museum. Wunderlich purchased it at the auction house of James R. Lawson and Little, Auctioneers located at 128-130 Pitt Street, Sydney on 25 November 1913. An account of the auction, published in the Sydney Morning Herald (SMH, 1913:20), described it as a "rare and valuable old Egyptian relic." The boat was brought to Australia, among a sizeable collection of "oriental" carpets, and sold by a Frenchman, Mr Jules Ratzkowski, "of Paris and Cairo" (SMH, 1913:20), an entrepreneur who traded in high-value antiques and works of art in North America, the Near East, Europe and even occasionally in Australia. Neither at the time of the deposition (25 November 1913) nor of the donation in 1962 did Wunderlich provide further information about the boat model. ${ }^{1}$ Its original provenance and history prior to the Lawson sale are thus unknown.

The boat model was on display at the Australian Museum for many years before being placed on loan with other Egyptian items to the Museum of Ancient Cultures at Macquarie University, Sydney in 1982. It has been examined by several visiting scholars whose assessments varied. Some attributed it to the Middle Kingdom, as funerary boat models are mainly associated with this period of Egyptian history, while others expressed orally their doubts about its authenticity. However, with the exception of Merriman (2011), these views have not been published. Merriman (2011: 437) made a brief assessment based on a photo of the incompletely assembled model ${ }^{2}$ while it was on loan to Macquarie University and concluded that "attributes reflected in classification [in which this model is included] suggest that [it is] not authentic" (Merriman, 2011:437). A recurrent objection to the model's authenticity has been the lack of comparable examples of boat models with similar fittings and figures accompanying the mummy, particularly the combination of mummy, rams' heads, Anubis, and the flat-roofed canopy.

None of the previous examinations of the model were detailed and the question of authenticity was not systematically addressed; hence it remained unresolved. In this paper we present the results of various dating and analytical procedures and discuss the symbolic elements of the model boat that have been questioned in terms of iconic standards and compatibility.

We examined a body of evidence to evaluate and possibly affirm the identity of the boat. Part of this evaluation involved gauging the probability of the boat being authentic against the probability of it being a pastiche. However, we must avoid a simplistic dichotomy-genuine versus false-as many ancient artefacts can be considered within a spectrum, ranging from a deliberate fake (intended to deceive) through to authentic. Objects reused or repurposed as well as the ancient duplication of iconic or earlier pieces provide numerous examples where authenticity is not entirely black or white (Lowenthal, 1992).

We evaluate the boat as an artefact made in a particular time and place, no matter how broadly defined. We are aware that many aspects of the boat's identity may not be comprehensively addressed or resolved, but a significant body of scientific analysis and historical comparative study allows us to present a set of conclusions, which in combination clarify the boat's authenticity and identity.

\section{Historical context}

\section{Funerary boat models}

Wooden boats associated with kings' burials were prevalent during the Old Kingdom. These were often large, life-size, or even over-sized, and were either real or models. They were gradually replaced by smaller boats and models, approximately 1-2 $\mathrm{m}$ long or smaller. These small models proliferated in burials, sometimes as fleets in impressive quantities (over 50), during the 11th and 12th dynasties (2140-1780 BC 3 ; Petrie \& Brunton, 1924:7). While the large boats can be interpreted as offerings, with significant expenditure of materials and labour emphasising the power and greatness of a buried ruler (Mark, 2012:126), small models seem to predominantly fulfil a magical and ritualistic function, providing vessels for afterlife spiritual journeys (Creasman \& Doyle, 2015:92-93; Eschenbrenner-Diemer, 2018).

The AM E60381 boat has been predominantly attributed to the Middle Kingdom (c. 2140-1660 BC) which probably also includes the First Intermediate Period (c. 2200-2140 $\mathrm{BC}$ ), because funerary boat models are essentially exclusive to this era. However, stylistically the AM E60381 boat is so different to models of this time that we must critically examine this attribution. Furthermore, the unusual shape of the hull combined with ram heads and Anubis would suggest the boat has, on first impression, more in common with a sizeable assortment of modern spurious boat models (Merriman, 2011:437; J. Taylor pers. comm. 18 Dec 2019).

The Middle Kingdom funerary boat models are often defined in reference to a few prominent museum pieces, 


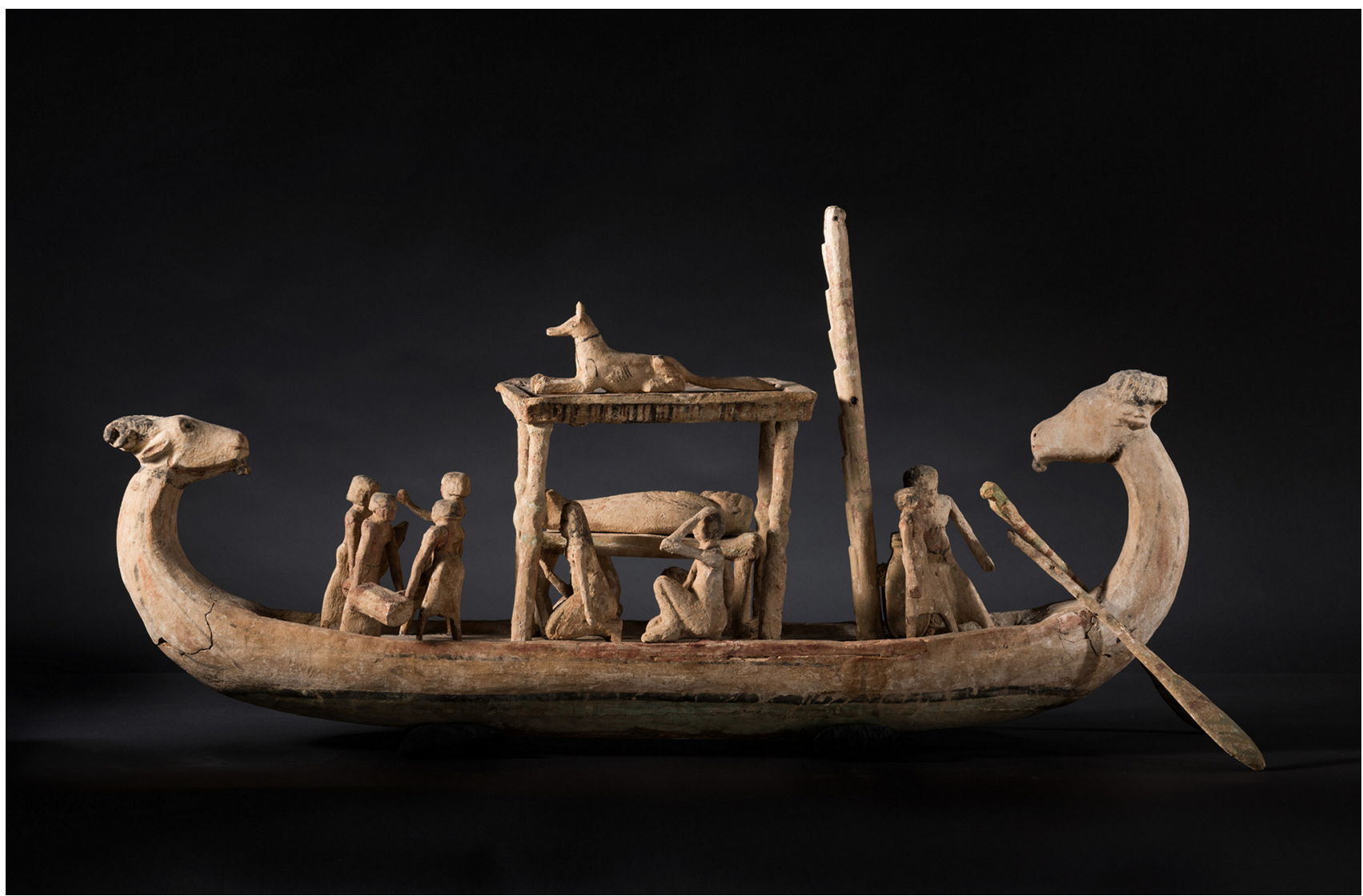

Figure 1. Funerary boat model (E60381), portboard (left side)— mummy is facing the wrong way. Photo by Stuart Humphreys (Australian Museum, Sydney). See also Plate 1.

many without good provenance. Boats from the Middle Kingdom are typically characterized by the hull, normally carved from a single block of wood and reasonably wide (beam in proportion to length ${ }^{4}$ ). The draft of these boats looks unrealistic and the underwater profile is distorted. "Since the Eleventh Dynasty model makers carved the hull deeper than that of an actual boat and made the bottom flat, so that the model would stand securely" (Winlock, 1955:46; also Reisner, 1913:IX). Thus, such a "high" hull became a stylistic marker of funerary boats of this period. Both prow and stern finials imitate an old-style raft-boat made from papyrus stalks (Müller-Römer, 2013:4) and these boats are often called papyriform (Jones, 1990:16); and their prominent life-size example is the 4th Dynasty $(2625-2500$ BC) King Khufu's boat from Giza (Jenkins, 1980; Lipke, 1984; Mark, 2009).

"Numerous representations in tombs and temples of the New Kingdom depict papyriform boats $[. .$.$] in the context$ of funerary or religious ceremonies, and are shown being used as funerary boats to transport the deceased's mummy across the river to the necropolis on the west bank, or as pilgrimage boats in which the deceased journeyed to the sacred sites of Abydos and Busiris" (Jones, 1990:60). The papyriform seems to be consistently "connected with funerary rites and the Under World" (Reisner, 1913:XXVII; also Rich, 2013:77).

The Middle Kingdom funerary boat models have hulls painted green and the ornamental finials at the prow and stern are yellow. Sometimes even the lashings of the leather sheaths that supposedly covered the prow and stern of such boats are depicted (Yamamoto, 2015:254). Typically, there is no mast or rigging, as such vessels would not travel under sail, but rather would be towed. These models have two steering posts aft that are capped with falcon heads looking forward and two steering oars placed in their position are manned by a single helmsman. Amidships is a canopy painted white with broad yellow borders inside and out. The canopy slopes down from front to back in a modest curve in the usual Egyptian manner. Under the canopy is a mummy lying on a bier with head directed forward, accompanied by "two mourning women, one at either end of a canopy" (Glanville, 1972:43-45). According to this definition, the AM E60381 boat with its rams' heads, Anubis, the flatroofed canopy and two pairs of mourners accompanying the mummy is incompatible with the funerary models of this period.

In addition to the unprovenanced museum pieces, the AM model can also be compared to model wooden boats found among small-scale artefacts recovered from numerous tombs, particularly from the Middle Kingdom (Lane Fox, 1875; Reisner, 2013; Tooley, 1989). Funerary boat models are reasonably common in this period. For example, several boats were found in the burials of Queen Neith (consort of Pepi II) of the 6th Dynasty, and Pharaoh's official Meketre during the Middle Kingdom (Jones, 1990:2). The tomb of local official Djehutynakht and his wife in Deir el-Bersha (Tomb 10) had about 58 model boats (some in fragments), which makes it the largest collection known from a single 
tomb and the best assemblage representing such models from the Middle Kingdom (Freed et al., 2009). Also, 35 boat models were found in the Tutankhamun tomb alone, New Kingdom (Jones, 1990:3).

These tomb boat models are very diverse, making attempts at categorization difficult. Among the categorization attempts (see, for example, Tooley, 1989; Jones, 1990; Glanville, 1972; Reisner, 1913; Strudwick et al., 2006:84$85)$ the Merriman (2011) classification system is the most comprehensive. Merriman's (2011) system is based predominantly on maritime attributes of hull construction and additional non-structural attributes. This classification system produced several distinct taxonomic-chronological groups in the 586 models classified by Merriman. However, this taxonomic-chronological grouping gives the impression that many models were incorrectly assembled, contain pastiche elements or parts adopted from other stylistic categories, including incongruous paintings or colour schemes as the hull-construction classification system does not align easily with the stylistic-decorative attributes or the nature of depicted episodes.

A particularly relevant subset of the Merriman (2011) catalogue for this study is the subset of funerary boats, which account for $11.5 \%$ of all known wooden boat models. These boats are identified as funerary by the presence of the following representations: a mummy (17 cases), mummiform (20), coffin (12), sarcophagus (5) or bier (5). Of these, 21 models are dated or attributed to the 11th Dynasty and 33 to the 12th Dynasty ${ }^{5}$ (cf. Tooley, 1989). They range in length from $46 \mathrm{~cm}$ to $154 \mathrm{~cm}$. They do not constitute a separate classification category, but consistently show two forms of hull construction-a planked hull constructed from timber planks, and an asymmetrical hull where bow and stern are clearly differentiated (Merriman, 2011; cf. McGrail, 2001:38-40).

Boat models without a mummy or its substitute can also be considered funerary. For example, some of the finest and well provenanced representations of the papyriform model are two boats from the tomb of Meketre in Thebes. ${ }^{6}$ Neither has a mummy on board and one is fitted with a mast and a crew of sailors, the other with 16 rowers. They both imply a spiritual pilgrimage to Abydos (Yamamoto, 2015:254). Some two-dimensional images from tombs in Beni Hasan illustrate flotillas of boats involved in funerary proceedings which suggest boat models without the mummy may be an integral part of funerary ceremonies - many boat models from the same necropolis could be interpreted as part of a spectrum of funerary rites (Merriman, 2011:79-80).

The divine barque (solar boat) in which the God Ra traverses the sky each day and passes through the underworld at night, is frequently depicted in two-dimensional images, but extremely rare among boat models. This invites an interesting question, were solar boat models so rarely made or not placed in the sepulchral context, that few have been preserved? As a rule, solar barque models are not associated with burials, but there are a few exceptions where such models (showing mystical symbols associated with $\mathrm{Ra}$ ) were found, usually incomplete or repurposed (Merriman, 2011:102-104).

Merriman also surveyed 159 models that were forgeries or souvenirs. In general, this group is characterized by a combination of Old and Middle or Middle and New Kingdom attributes in the same object. Also, they largely show a symmetrical hull which is uniquely present in the distinctive category of New Kingdom models and the solar barques, but are absent from all other authentic models. In the forged/questionable models human and animal heads often decorate prow and stern, and ram heads are frequent. The full finials at hull ends are often incorrectly and flimsily attached, as if a maker lacked understanding and experience in model construction. Many models have Anubis (jackal), on the canopy. A large portion of these models are single piece; composite models are fanciful, brightly coloured, clumsy and some outright cartoonist. On examination most of them appear to be pastiches, meaning they reflect how modern forgers imagined ancient Egyptian models rather than consisting of dedicated replication of well-known antique examples. Most can be readily marked as clumsy impostors. They are almost exclusively reproductions of funerary models, to display, we can assume, more flamboyant visuals than non-funerary models permit and therefore attract more attention from souvenir hunters. It is easy to understand why the combination of ram heads, Anubis and mummy seen on the AM E60381 model evokes the spurious boat models and sounds an alert to scholars.

When the tomb of Tutankhamun was opened in 1922, among its rich contents was a travertine boat model with two ram heads, adorning a water tank. It is a credible supposition that this visually attractive motif was enthusiastically adopted by creative forgers (Merriman, 2011:452). It is worth noting that the AM E60381 model predates the opening of Tutankhamun's tomb in 1922.

The AM E60381 model, with its symmetrical hull and notorious ram heads, was placed by Merriman (2011) in the group of questionable models and also in a supplementary sub-group with two other models with human and animal heads. She speculates that all three boats were made by the same workshop or forger. However, the two other models are in many respects crude and garish, quite different from the AM E60381 model where ram heads are carved with anatomical precision and aesthetic grace, and where the proportion of human figures gives an impression of balance and spaciousness, typically absent from fake examples. Merriman (2011:437) also observed that the AM E60381 model "carries the only human figures on these models that appear authentic".

This brief outline of classification demonstrates that the AM E60381 model does not conform to the Middle Kingdom standard or, for that matter, any authentic funerary boat model. It also shows that the classificatory method based on form (structural and symbolic attributes) is often insufficient to prove or disprove the authenticity of the model.

\section{Boats as symbols}

In the search for comparative references we must look further afield, beyond narrowly-defined funerary models. The AM E60381 boat shows some characteristics of a solar barque associated with gods and kings as deities. The hull itself is a "vessel" of significance as suggested by divine barques which were not floated but carried by priests and rested along the way at the divine rest stations (Romer, 2017:348-353). The vessel contained a portable shrine in the middle - a central and essential element of devotion. The prow and stern were decorated with symbolic 
representation associated with a deity, such as a falcon's head with lunar crescent and a disc for Khonsu, a woman's head for Mut and a ram's head for Amun. In contrast, the AM E60381 model is a vessel where a mummy under a canopy is an equivalent of a shrine, while the prow and stern are fitted with the symbols of a deity to whose protection and support the deceased person would have reason and entitlement to appeal.

Other elements of funerary boats have less divine character in the form of the mourners, boat crew, and other "passengers." They seem to combine the sanctity of a funerary procession with the pragmatic reality of a funeralfrom mourning and delivery of funerary goods through to propelling and navigating the boat. Model boats considered as funerary have at least a mummy and almost invariably a canopy. Other elements come in various permutations. Some miniature boats have nothing but a mummy, other larger boats have a variety of figures. Most funerary boat models illustrate the journey of the mummy in the company of ordinary and earthly characters, such as mourners and priests, rather than divine beings. Figures that can be identified as deities or their associated symbols are infrequent.

Boat models may be divided into ordinary and spiritual. Ordinary models represent roughly realistic watercrafts that would have been used to transport goods, travel, fishing, or other purposes. They depict daily scenes of secular or perhaps unspecified ceremonial journeys. The other group consists of boat models fitted with representations of explicitly supernatural, symbolic characters. However, according to Jones (1990) all boat models would be required by an individual after death to fulfil religious obligations such as "pilgrimage to Abydos or Busiris, or to carry his mummy to the tomb, or to enable him to [...] cross to the western horizon of the sky and join Re' in his bark, without having to rely upon the favours of the Ferryman. These purely magical boats, in contradiction to the former which, although magical in the broad sense of the word, were to be used in the next life in much the same way, and for similar purposes as they had been used on earth" (Jones, 1990:2). All boat models, along with other accessories, would play some role in the funerary rituals and indeed could have been considered a necessity (Creasman \& Doyle, 2015:89). "The belief was that the deceased would [...] board successively two boats in which the sun god crosses the sky by day and travels through the underworld by night, a voyage that leads to resurrection each morning" (Arnold, 2015a:19; cf. Abubakr \& Mustafa, 1971).

The AM E60381 boat is "magical" in this sense and although it does not strictly conform to the narrowly-defined funerary model it shares at least some commonality of purpose with all boat models deposited in tombs.

The relative symbolic value of boat models could be viewed on a continuum with the apparent representations of ordinary daily scenes at one end and models with deities at the other. The priests, mourners, and the mummies themselves appear to bridge these opposites, blending them in the diversity of imagery, arrangement of figures and symbols of a sacred nature. This diversity of models makes it possible, or even necessary, to consider that different elements and symbols were on occasion rearranged and reassembled in novel combinations.

The AM E60381 boat displays a combination of symbols (ram heads, Anubis and mummy) unknown in other boat models. Can this be justified in the context of the transition to the Middle Kingdom? It is recognized that a dramatic shift occurred in the middle of the 12th Dynasty, that is around the middle of the 19th century $\mathrm{BC}^{7}$ (Callandar, 2000). The god Amun (or Amun-Re), worshipped at least since the 5th Dynasty (Redford, 2002) was elevated to the highest status as a result of political strategies, dynastic ambitions and the need for sacred-sanction of legitimacy of Theban kings of the 11th Dynasty (Arnold \& Arnold, 2015:38; Silverman et al., 2009:X). All changes discernible in historical records suggest the Theban kings of this period redefined the cosmological, ideological and religious narrative of Egypt, re-setting time (calendar) and the geographical centre of the kingdom (Romer, 2017:346; Grajetzki, 2006). The changes visible in architecture, art and other areas of life reflect a significant shift in religious beliefs, practices and connections between humans and deities who, it was believed, determined the fate of mortals (Silverman et al., 2009:XI). For example, "models of workshops, food-production facilities and domestic structures, which first appeared in Late Old Kingdom tombs and were prevalent in the Eleventh and early Twelfth Dynasties, vanished in the mid-Twelfth Dynasty [...] The making of model boats seems to continue for somewhat longer period" (Oppenheim, 2015:6; also see Quirke, 2015:221; Eschenbrenner-Diemer, 2018:101).

"During Middle Kingdom non-royal individuals were permitted to include in their tombs the type of objects, iconography and inscriptions that seem previously to have been reserved for kings" (Oppenheim, 2015:8). Non-royal individuals were allowed access to a wider spectrum of symbols and presumably different types of rebirth "along with some of the beliefs related to afterlife - that changed during the Middle Kingdom" (Oppenheim, 2015:8). It is probable that a wide participation of the "middle class" in the ritual of resurrection resulted in the proliferation of small boat models in this period (Rich, 2013:73-74). The annual Amun Boat Procession from Karnak to the royal funerary temples on the West Bank, which later became one of the great religious festivities of the New Kingdom, probably began under Mentuhotep II ${ }^{8}$ (Arnold \& Arnold, 2015:40-41). Concluding on the symbolism of King's Senwosret III (c. 1878-1839 BC) burial complex at Abydos Wegner remarks: "The use of divine symbolism associated with Anubis as protector of the royal burial place at South Abydos embodied very explicitly in the form of the $\underline{d} w$-'Inpw, Mountain-ofAnubis, and developed in the necropolis seals of both South Abydos and later in the Valley of the Kings" (Wegner, 2009:160).

Deities of ancient Egypt, their relationship with kings and associated iconography are complex. King Mentuhotep IIfounder of the Middle Kingdom-was depicted in the guise of the god in the chapel at Dendera, wearing a cap with tall feathers associated with Amun, and as a helmsman of Amun's skiff at Karnak (Arnold \& Arnold, 2015:40). Furthermore, Amun was associated with the image of a ram - the symbol of fertility, sometimes depicted as a man with ram's head or as a ram. ${ }^{9}$ This association is clear in the images of Amun's sacred barque in the temple complex at Karnak, best represented by images related to the New Kingdom (Murnane, 1979). An image from the hypostyle hall at Karnak depicts a procession with the sacred bark of Amun-Re where the three rows of five priests holding the bars in the rear of the bark are wearing the masks of Anubis (Sullivan, 


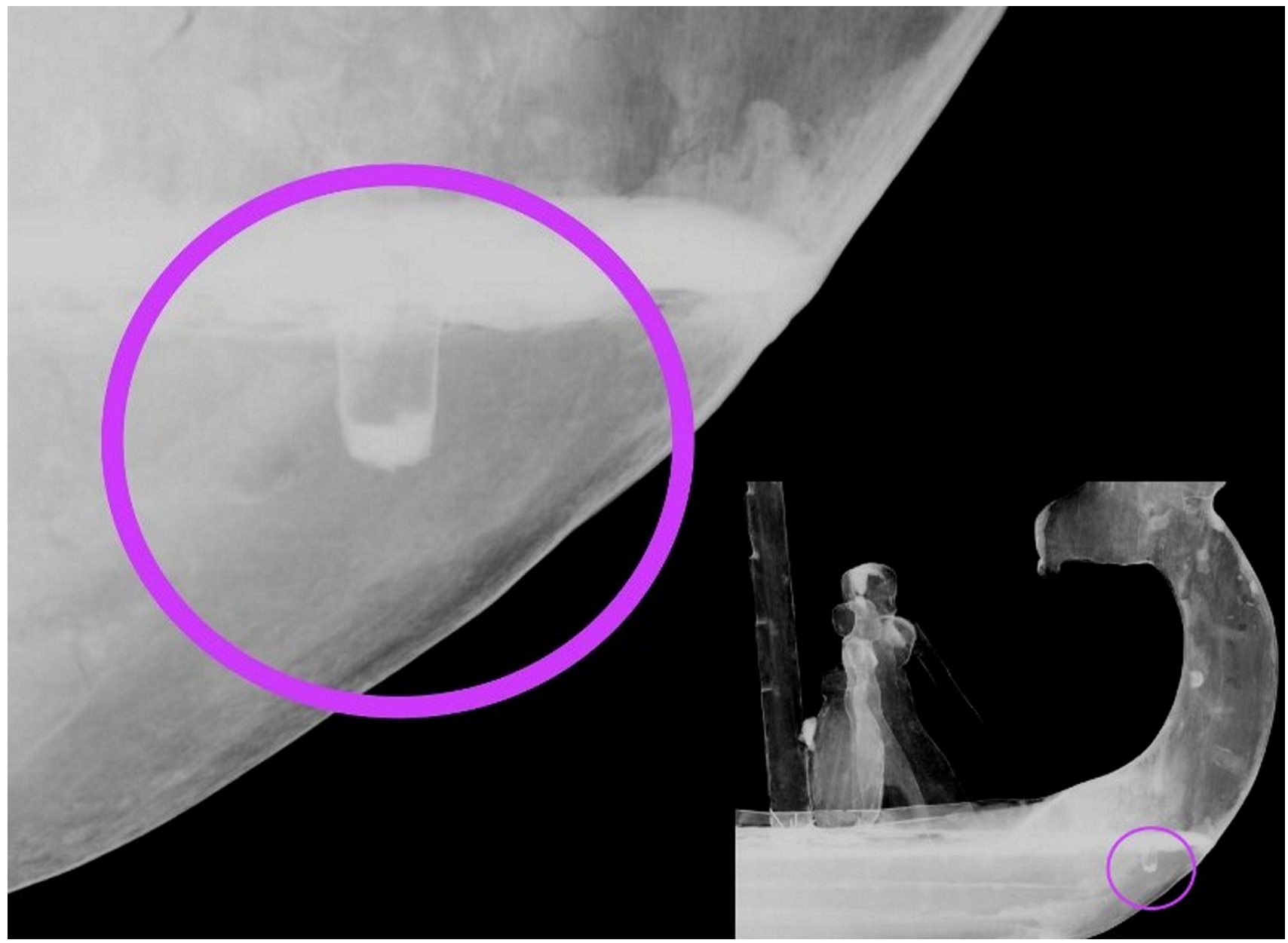

Figure 2. X-ray showing peg attachment of ram's head to the hull (right side).

2012:3). Anubis is associated symbolically with overcoming chaos and would suggest stabilising influence in assisting god Amun-Re in the boat procession as vizier, as well as playing a part in the transformation of the deceased from this life to another form of existence (Arnold, 2015a:19). "The portable bark of Amun-Ra was carried on five carrying-poles by thirty shaven-headed waab-priests, often shown wearing Horus- and Anubis-masks as representatives of the 'Souls' of the ancient cult centres of $\mathrm{Pe}$ and Nekhen, in six rows of five. Before and behind the bark walked other priests carrying fans and, on the either side, the king and the more senior members of the clergy" (Jones, 1990:11).

The best parallel in overall boat design is an incomplete boat model in The British Museum with two ram heads facing forward and attributed to the New Kingdom (EA9505). It was purchased from the collection of the second Earl of Belmore in 1842, but has no specific provenance (Glanville, 1972:62; BM EA9505; Merriman, 2011:99, 203). The boat has a distinctly shallow draft, broadly comparable to the AM E60381 model and is about $28 \mathrm{~cm}$ long (BM EA9505 ${ }^{10}$ ). Both ram heads are cut flat at the top and a vertically oriented hole is drilled through, probably for inserting some insignia (such as displayed on the sacred barque of Amun). Both ram heads seem to have remnants of wigs in carving and blue paint. The hull is made from at least two separate parts; the port (left) side is carved separately and attached to the solid hull. The ram head at the prow is also carved separately and attached with (probably) dowel and unspecified adhesive (Glanville, 1972:62). Two holes on the starboard side, mirrored by similar holes on the port side, suggest they were for supports to hold an on-deck shrine (or other structure). The hull was painted yellow and green. Carving seems ordinary and its "plainness" combined with its size is regarded as a plausible indication of authenticity (Merriman, 2011:99). Despite missing fittings and possibly figures, this model displays the characteristics of the Sacred Barque of Amun (BM EA9505), comparable to better known examples from two-dimensional representations in Egyptian art.

In any event, the boat with ram heads and mummy instead of a shrine on board is unusual, but not beyond comprehension in times of political change and spiritual creativity that defined the First Intermediate Period and the early phase of the Middle Kingdom.

If funerary boat models evolved directly from some variants of the divine barque and first appeared not long before the 12th dynasty, as Reisner postulated (Reisner, 1913:XXII), we would expect to find, if not strictly transitional forms, at least the eclectic models combining elements of divine barque with funerary boat. The AM E60381 model may be an example of such a hybrid form. This hypothesis would be stronger if the model originated around the First Intermediate period or broadly in the period of transition from the Old Kingdom to the early stage of the Middle Kingdom (Eschenbrenner-Diemer, 2018:101). 


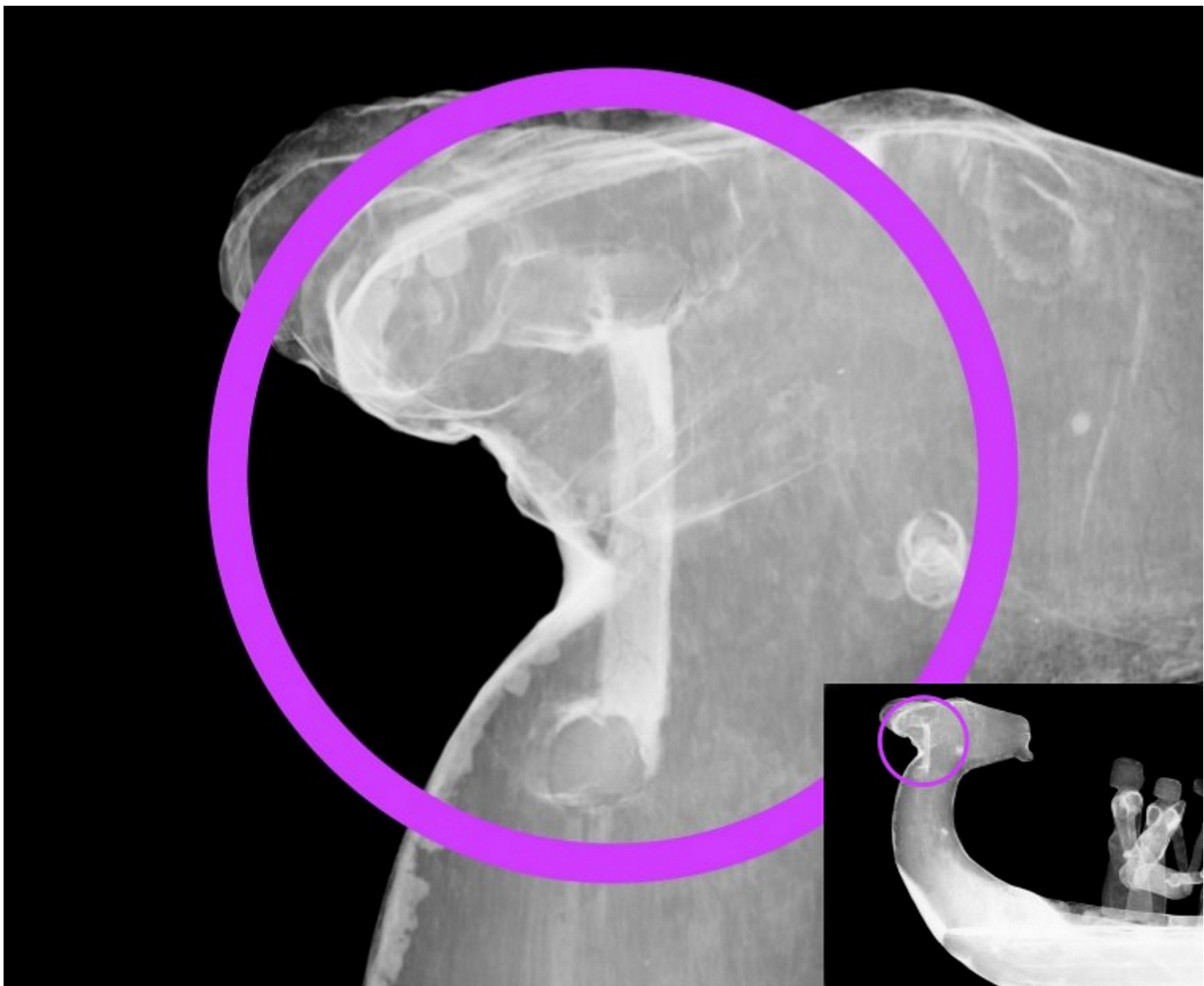

Figure 3. X-ray showing two holes drilled in ram's head, horizontal for pegging horn protrusion and vertical for inserting head insignia. Image by Paula Dredge, adapted by S. Florek.

\section{Technical analyses}

\section{Construction, paint, and timber}

The AM E60381 boat is $105 \mathrm{~cm}$ long, $22 \mathrm{~cm}$ wide and 38 $\mathrm{cm}$ high (including stanchion). The oars are about $35 \mathrm{~cm}$ long. It is made from several pieces of timber which typify ancient Egyptian woodwork, including the use of off-cuts. Scarcity of timber compelled artisans to make wooden objects, whenever technically feasible, from separate pieces fitted neatly together. This applies to larger objects such as coffins and actual boats and was commonly used in small objects such as models. For example, the hull of model number 4918 in the Cairo Museum is made from several "irregular pieces set in and fastened with pegs. Several cracks have been filled with wood. The whole smoothed over with plaster and painted" (Reisner, 1913:78).

X-ray images of the boat, combined with some old conservation photos, ${ }^{11}$ taken when the boat was (still) partially disassembled in the 1970s, provide reasonably good insight into its construction. The entire hull was made from at least five separate pieces.
The core of the boat is an elongated block of wood, flat on both sides and with a flat upper surface. This block extends for almost the entire length of the boat and makes up nearly one third of its width in the middle. The upper surface forms part of the deck and is visible under a thin layer of gesso. The bottom ends of the block are shaped to follow the contour of the upwards curving hull, while on the top, at both ends, separately carved ram heads are affixed with a single dowel and adhesive (Fig. 2), forming decorated prow and stern.

Both ram heads were carved from a single piece of timber. The lower head, presumably the prow, has a hole (about $2 \mathrm{~cm}$ deep) drilled vertically towards its back, between the bases of horns (Fig. 3), possibly for inserting a symbolic element (such as a sun disc). The horns of both rams are absent. We can infer that horns, as the most delicate protruding elements of the model, were especially prone to damage. They were broken off and only their bases are present. The broken surfaces are not identical. For example, one shows solid timber, suggesting that at least some length of protruding horn was carved from the same piece of wood as the head itself; the other shows a hole drilled for attaching a protruding extension at the base (Figs 3 and 4 ). The absence 


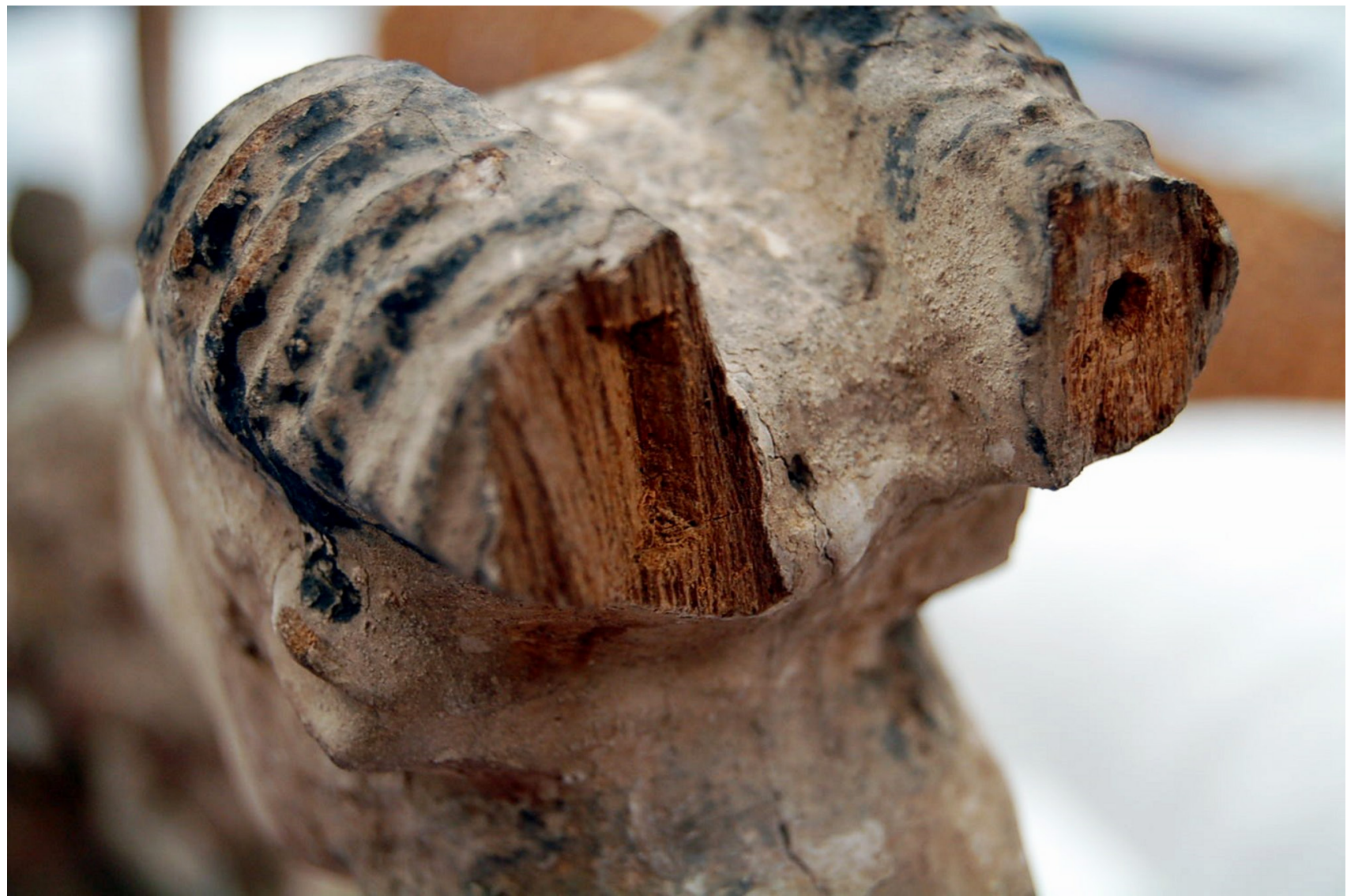

Figure 4. Back of ram's head showing two bases of broken horns, one in the left-solid timber, the right one with hole for pegging horn extension. Photo by Heather Bleechmore.

of (detached) horns indicates they were broken and lost before the boat was presented for sale at the auction in 1913. We are unable to say if the horn's attachment with dowel to the ram head was an entirely original repair or a later attempt to repair the model.

It is not known if one of the ram heads was detached by mishandling the object or its exposure to unfavourable environmental conditions through the 20th century (or earlier), or both. The 1970's photos show that the heads were broken roughly at the base of the elongated neck. One head (prow) was actually detached with only a part of its base remaining in place. This exposed a front section of the central block of timber and two side pieces.

As X-ray images (Figs 2, 3 and 5) reveal, on each side of the central block is an elongated piece of wood shaped in the form of the hull. Each curves downwards and towards the front and back to form the distinct shape of the vessel. The upper, outer edge of these modelled pieces forms a narrow gunwale, not even one centimetre high; one of which was split-damaged and reattached with a few small nails.

The X-ray images obtained so far show one dowel joining the central block to the side piece (Fig. 5). No other joinery between the separate elements is clearly discernible in current X-rays. It looks as though three major parts of the hull were assembled with a few dowels and an unknown adhesive (bovine, collagen-based adhesives were commonly used in woodwork at that time, Newman \& Serpico, 2000:476). The reliance on adhesive can be understood as the function of the boat model was not mechanical but purely symbolic.
It is noteworthy, however, that the adhesive kept the hull (mostly) together for a long time.

The overall analysis of X-ray images shows the sharpest and most visibly outstanding features are the marks left by the small nails (recently removed) used in minor repairs after the model was taken out from its (probable) burial context. Long and slender, pin-like nails must have been industrially produced and are unlikely to predate the (late) 18th century. All other construction-related features and marks, such as dowels, holes drilled for them and other attachments, and possible marks of timber carving are visible in much softer or shadowy resolution. The second sharpest feature seems to be demarcation lines between the central block of timber and side-hull pieces on both sides. Such distinction suggests a considerably long period of time elapsed between drilling the holes for dowels and using the nails for repairs. This time cannot be quantified but it probably would be measured in centuries, not decades.

There are ten human figures on board. All are pegged to the deck, typically with one dowel. Some arms are separately carved and attached to the torso. Four of the figures are squatting female mourners, two on each side of the mummy. Some mourners raise arms to their heads in lamentation, in accord with distinct Egyptian mourning iconography (Quirke, 2015:223).

Six other figures do not seem to be directly interacting with the mummy or with the vessel through implied navigation, lookout, or steering. Four standing figures in the front, in two pairs, seem to handle two sizeable objects. 


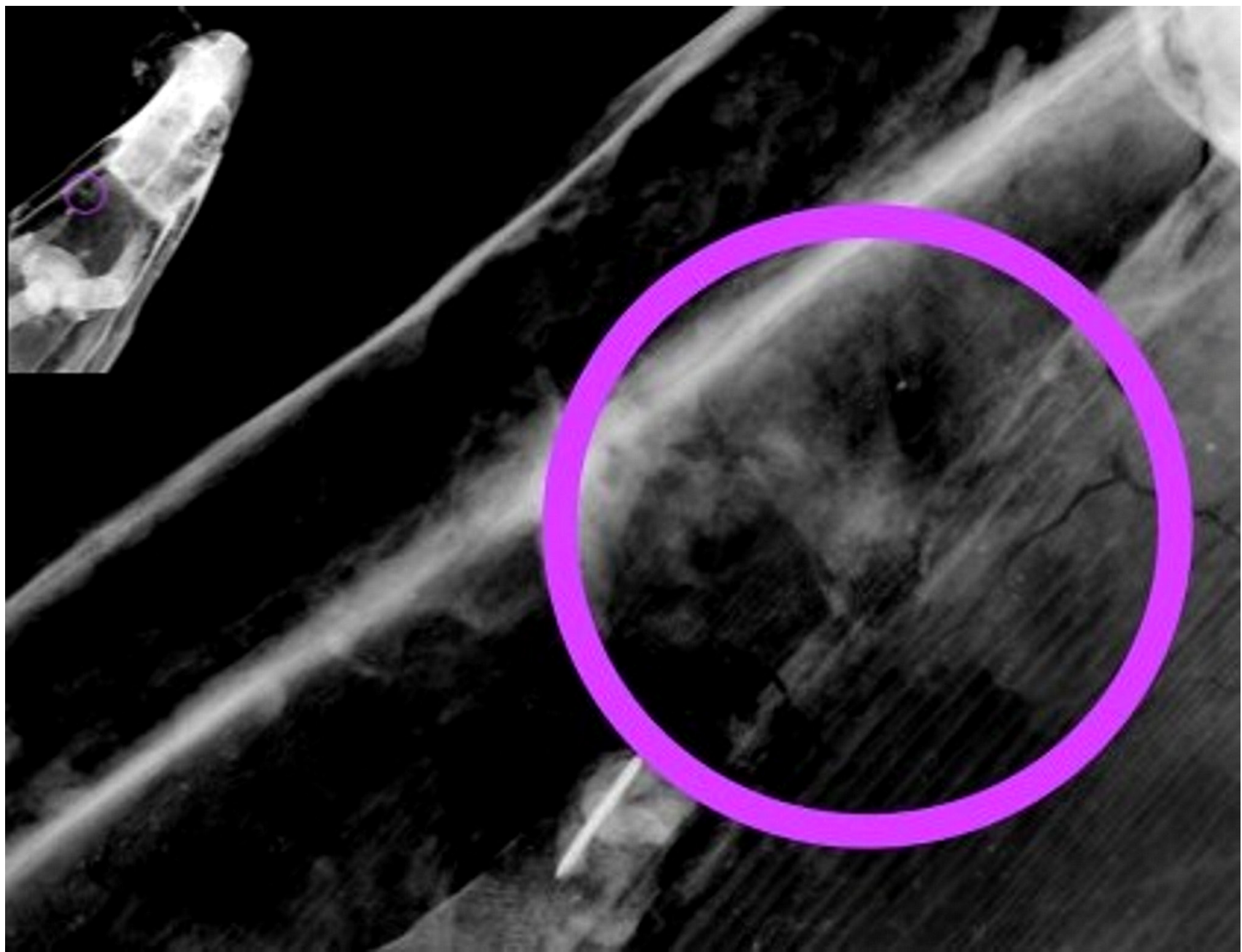

Figure 5. X-ray showing peg joining central block of timber with hull's side piece. Image by Paula Dredge, adapted by S. Florek.

One looks like a large mallet, the other an elongated object tapering at one end to a blunt point, broadly similar to a wine amphora (or other sizeable container). Two figures in the back are facing the stern and it is possible that they are meant to hold steering oars (Fig. 6). The remaining boat fittings give no indication as to how the oars were originally placed in relation to the boat and figures on board. However, we should not assume the model was arranged in its original setting in "floating position". Just behind these two figures is a pole that, via inference from other models, would support the fitting and operation of steering oars. The pole has eight notches on its shaft and two small holes drilled through, one between the 4th and 5th notch (at the level of the canopy) and the other near the top. Next to the pole is a sizeable vertical object that looks like a large pottery-container, reaching almost to the lower chest of the figures.

The entire boat was coated with a layer of gesso and painted. The pigments are mostly faded and it is not possible to comprehensively reconstruct, with the naked eye, the actual pattern of the painting. Many, if not most, wooden Egyptian models have their original paint significantly degraded as illustrated by conservation work at the University of Pennsylvania Museum of Archaeology and Anthropology (North, 2015). However, some remnants of the painting indicate manifest attention to detail.
The port side of the hull seems to have paint preserved better than the starboard side. A horizontal black line that runs roughly at one third of the hull's height from the bottom could indicate a watermark. It is difficult to tell if the colour below this line has a tinge of green or blue, ${ }^{12}$ but above the line the hull was painted red (Fig. 7). The red extends to the neck of the rams, where it becomes rather fuzzy. Remnants of black paint above the line at the prow-end could be what remained from the eye of Horus (wedjat), but it is far too incomplete to confirm. The colour of both ram heads and their necks is difficult to determine. However, both preserve some linear marks with black and possibly dark red-brown paint. The smaller, prow ram, has these marks better visible; it could be assumed that the other ram was painted in a similar manner.

The prow ram has the base of its (missing) horns and its goatee beard painted black; the dark red-brown paint follows the contour of the ram's jaws and the outlines of its ears. It has a black collar at the base of its head. From the collar four, roughly vertical, lines run down following the contour of the curved neck. Two of these lines are joined together at the collar and again at the base of the neck. The same pattern is faintly visible on both sides of each ram's neck.

All four sides of the flat canopy are painted with dark red-brown and black, short, closely-spaced, vertical lines (frieze-like) - a pattern frequently used to break a monotony 


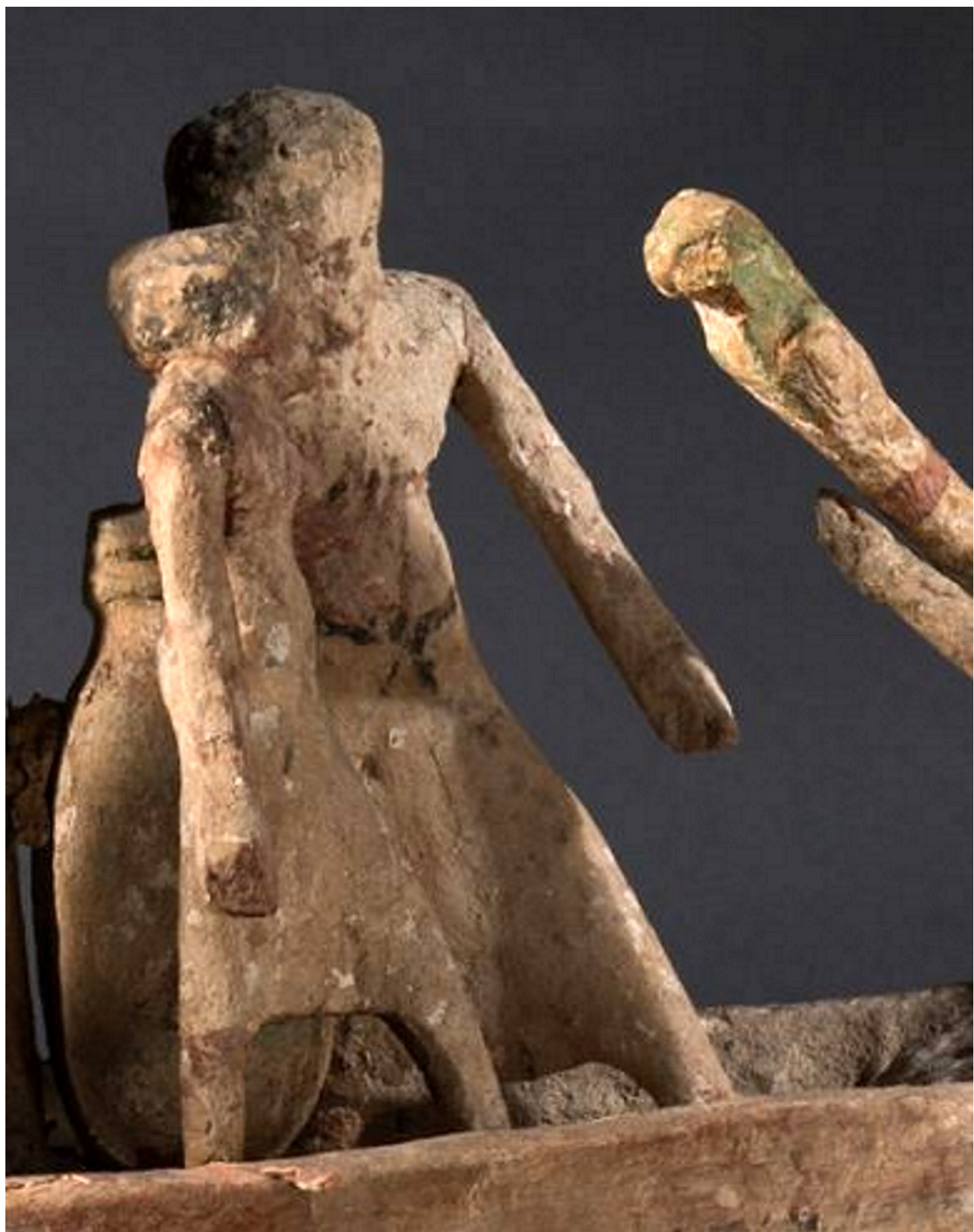

Figure 6. Figures on board, showing separately attached arms, belt around the waist (figure on the right), dark hair (both figures) and the falcon-like head of an oar. Photo by Heather Bleechmore.

of long and narrow horizontal elements in Egyptian art and architecture. In parts, the spacing of these lines is irregular and occasionally black over-paints the red, giving the impression of sloppy or hasty work (Fig. 8). Four round posts holding the canopy are modelled with two indistinct bulbous forms carved in the middle, one above the other. The bulbs have a touch of green or blue paint, divided by red. Below these forms the posts are painted with dark red-brown bands diagonally spiralling around the trunk. The painting pattern at the upper part of poles is unclear, but it has some remnants of dark red-brown bands.
All human figures have their hair painted black, now visible in residual form, and some have circular marks to accentuate their eyes (Fig. 6). Some faces and bare torsos show remnants of red paint while skirts are pale cream. A few figures have a black line painted around the waist, possibly marking a string or belt for holding the skirt in place (Fig. 6). All four mourners are squatting females, with slightly pronounced breasts but pale torsos, indicating long garments, covering most of their bodies.

The mummy has a painted face and some red/black pattern painted on its upper torso, resembling a large, semicircular, 


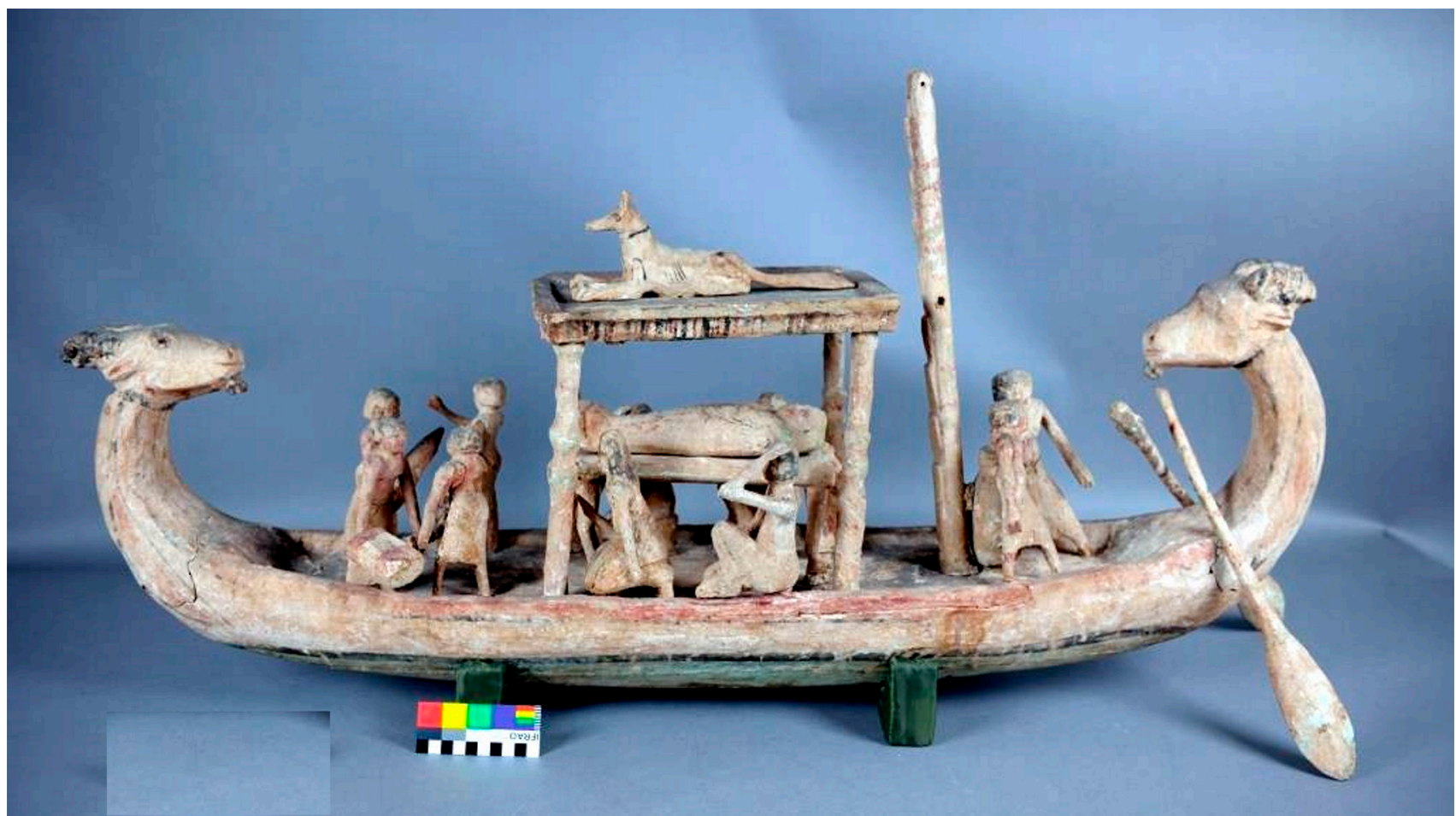

Figure 7. Boat model port (left side)— mummy is facing the wrong way. Photo from 1970s, Australian Museum.

broad collar draped over its chest. The thick elongated bier has lion-like legs. The jackal (Anubis) has a black collar, an $\mathrm{X}$-shaped cross on its chest, and lines accentuating shoulders of the front legs, ribs and paws. A sizeable cylindrical form (oblong in cross-section) of the mallet-like object held by two people at the front of the boat is painted red with one wide band of white in the middle. Its handle shows dark red-brown bands. The shaft of both oars is painted with red spiralling bands. The proximal end of one of the oars shows a falcon head (Fig. 6).

Pale, creamy, nearly white spots are visible on parts of the hull, fittings, and figures; they may be the remnants of white paint or gesso showing through the remnants of pigments. Several fragments of black paint, although also degraded, show up strongly against other painted colours. In addition, in some places (e.g., the canopy) black covers (sometimes clumsily) the red paint underneath, raising the question as to whether the black in particular may have been painted or repainted sometime later after the original painting was partially degraded.

All pigments are compatible with ancient Egyptian materials. It seems the Egyptian blue had enough time to decay and transform to green, still discernible in parts of the boat. The original painting faded away over time, mostly as dry particles of paint crumbled and fell off the surface. At some unspecified time later the black paint was selectively reapplied, as if to highlight fading paint "decoration." The second painting with black also had enough time to significantly decay. None of these episodes and processes can be situated on the time-line, but they suggest a time scale of considerable length.

Despite an impression of simplicity, the boat contains a variety of mineral and organic materials processed and combined in various ways. They include adhesive, gesso, and pigments. Analyses of these materials could reveal if and how closely they conform to usual ancient Egyptian materials. For example, we would expect that black pigment is carbon-based possibly obtained from (lamp) black soot; while red would be iron oxide or red ochre.

So far, we have confirmed through XRD (X Ray Diffraction) that the white pigment is calcite (calcium carbonate) with lesser quartz (silicon dioxide), while the gesso (SAZ 850 Raman-spectroscopy) is lime plaster. In the sample of green pigment the background material is calcite (calcium carbonate) with a little silica, but the green matches paratacamite, copper chloride-hydroxide $\left(\mathrm{Cu}^{2+}{ }_{2} \mathrm{Cl}(\mathrm{OH})_{3}\right.$ analysed by Ross Pogson) which is present in pigments used for colouring pottery and glass as well as paintings and in cosmetics in ancient Egypt (Pagés-Camagna \& Colinart, 2003). Use of paratacamite and atacamite as pigments in Ancient Egypt is known, but unusual, especially as malachite $\left(\mathrm{Cu}^{2+}{ }_{2}\left(\mathrm{CO}_{3}\right)(\mathrm{OH})_{2}\right)$ was so abundant and more easily obtainable. An alternative origin is suggested by the work of Giménez (2015), whereby a green pigment, mainly atacamite/paratacamite resulted from degradation of synthetic "Egyptian blue" pigment due to contact with chlorine-bearing solutions.

Samples of wood taken from the hull, deck, jackal, rear figure and a dowel were examined and imaged using the scanning electron microscope in transverse, radial longitudinal and tangential longitudinal sections (see Cartwright, 2015 and 2019 for details of the methodology). Comparisons were made with reference specimens from ancient Egypt and modern wood thin sections (Cartwright, 2017). The sample from the boat hull is from the wood of the local fig tree, Ficus sycomorus, which usually grows along the banks of the river Nile. ${ }^{13}$ This wood was used for making coffins since at least 5th dynasty (Abdrabou et al., 2015:3), and was particularly popular in the Middle Kingdom, both for coffin planks and for model boats (Cartwright, 2016, 2019; Amoros et al., 2012). 


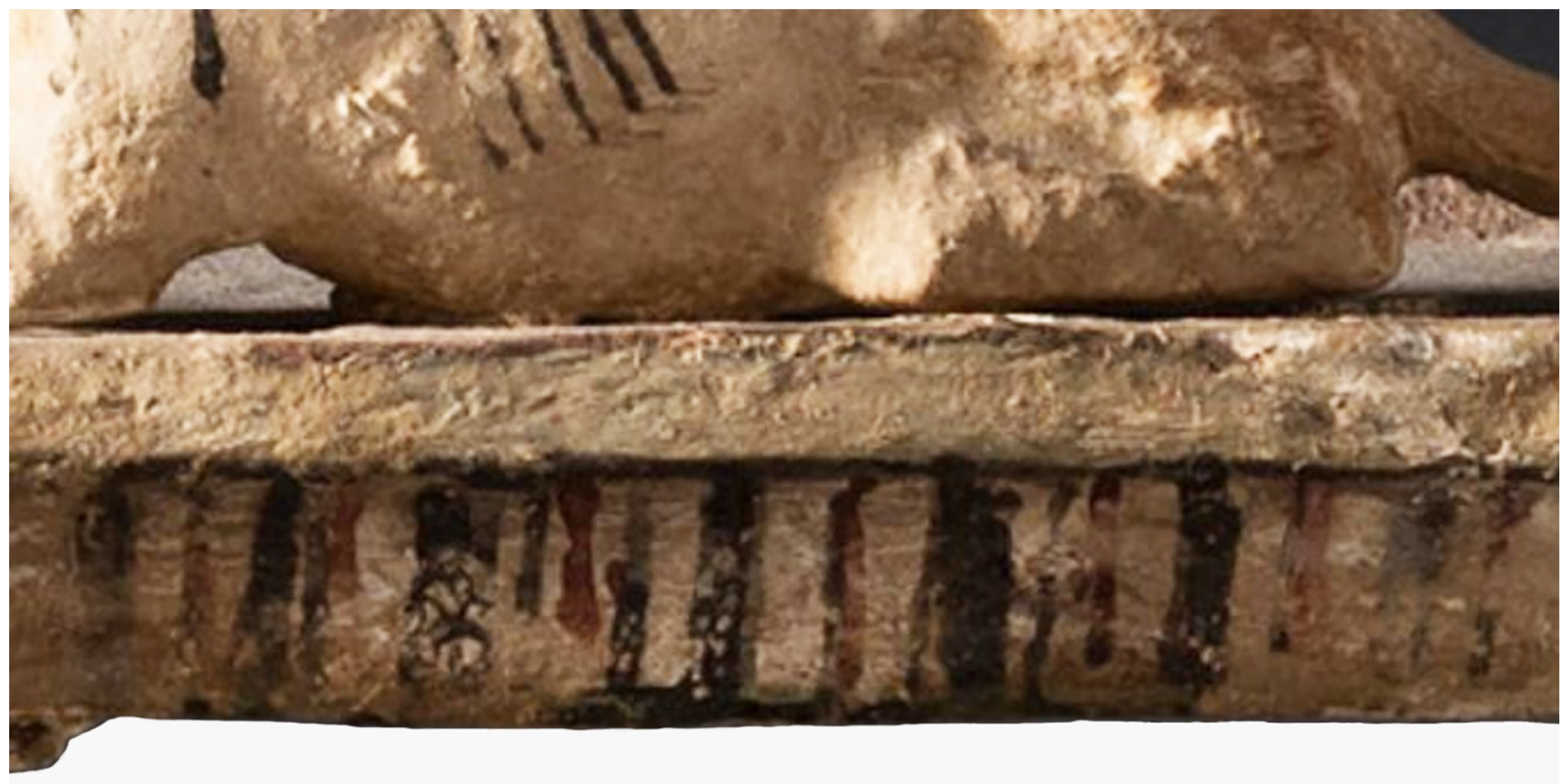

Figure 8. Section of canopy with red and black vertical lines; in places the black over-paint (earlier) red lines. Photo by Stuart Humphreys (Australian Museum), adapted by S. Florek.

The condition of wood (in the hull sample) is denser and harder when compared to the typical condition of Middle Kingdom Ficus sycomorus wood, which commonly is quite soft and prone to insect attack (Cartwright, 2017). However, wood condition (or quality) is not usually a reliable chronological indicator. Nonetheless it invites the question of wood recycling and reuse, given that original or reused timber might be expected to show more advanced deterioration. ${ }^{14}$

The deck of the boat was identified as the imported wood Cedrus libani (Cedar of Lebanon). Figure 9 shows the diagnostic scalloped tori of the pit margins very clearly; these features are diagnostic of cedar wood (Cartwright, 2004). Cedar of Lebanon wood is often considered to be easy to carve, plane and polish, although large knots and ingrowing bark can be problematic, and the wood may be rather brittle. Some species of Cedrus are renowned for being strongly aromatic and resinous (and therefore insect-repellent), but there is some debate as to the extent to which Cedrus libani trees routinely develop resin canals (Cartwright, 2019).
The wood of the jackal (Fig. 10), and the rear figure, like that of the hull, is Ficus sycomorus (sycomore fig). Although this local fig wood is of medium quality, light in weight and is susceptible to insect attack, it is easy to carve (Cartwright, 2013). When ancient Egyptian funerary objects or coffins made from fig wood have been heavily painted and decorated, the propensity of the wood to deteriorate as a result of insect attack, decay or physical damage can be reduced (Cartwright, 2019).

The wood of the dowel is Ziziphus spina-christi (sidr), (Fig. 11). It was important when constructing coffins and funerary objects in ancient Egypt for carpenters to choose woods of different properties for the interconnecting elements, such as dowels and tenons (Cartwright, 2016). By choosing woods that are hard or dense (such as sidr) for the connective elements, tight joins can be created. Sidr, found in tree and shrub forms, inhabits river-banks, desert wadis and scrubland thickets. Some of these habitats may restrict the straight growth of sidr, resulting in twisted or knotty timber, best suited for dowels, pegs or tenons rather than planks.

Figure 9 (facing page). Scanning electron micrograph of a radial longitudinal section of Cedrus libani (cedar of Lebanon) showing the diagnostic pits with scalloped tori in the tracheids. Electron micrograph by C. R. Cartwright, The British Museum.

Figure 10 (facing page). Scanning electron micrograph of a radial longitudinal section of Ficus sycomorus (sycomore fig) wood. Electron micrograph by C. R. Cartwright, The British Museum. 

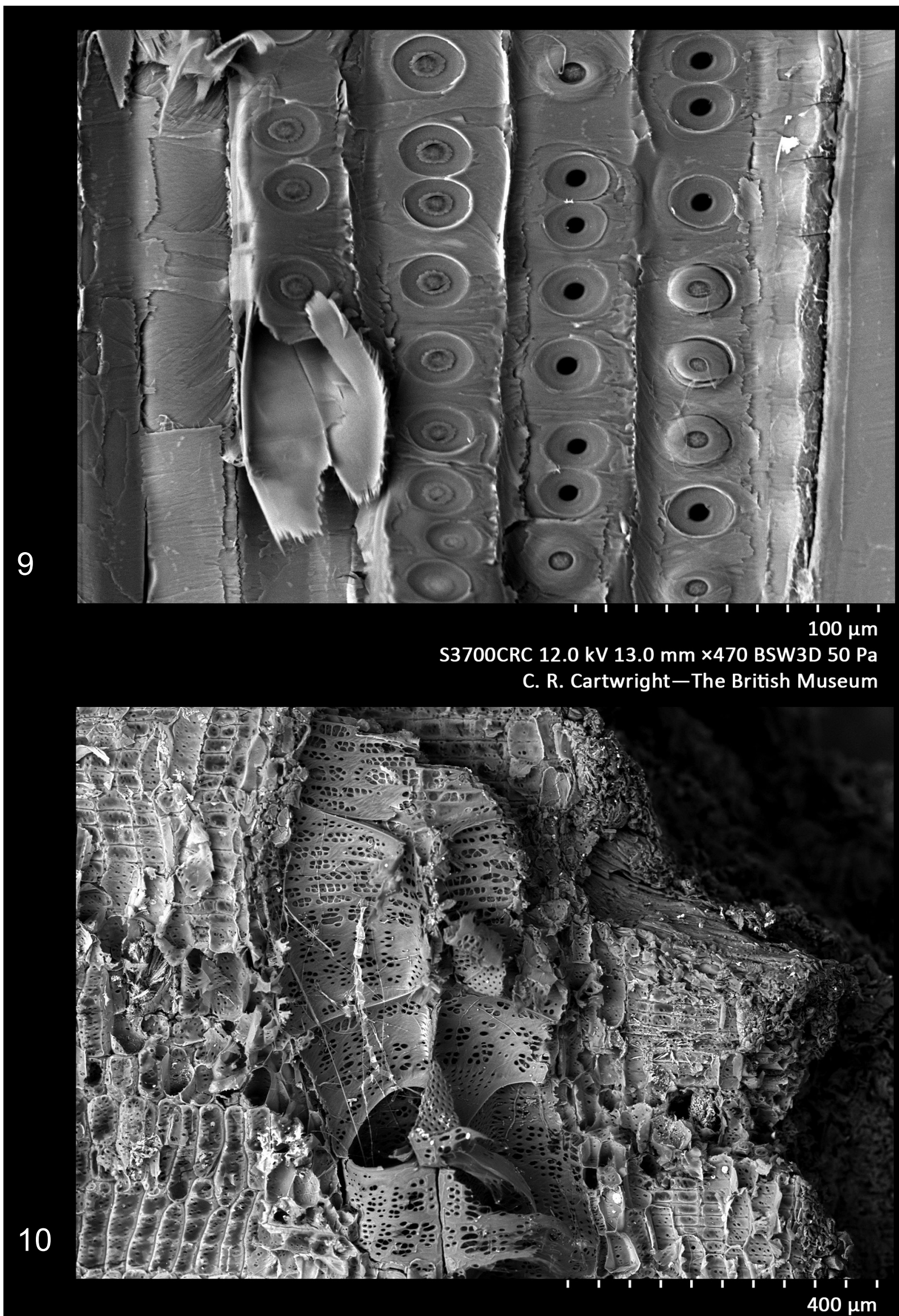

S3700CRC $15.0 \mathrm{kV} 14.5 \mathrm{~mm} \times 120$ BSE3D $40 \mathrm{~Pa}$ C. R. Cartwright, The British Museum 


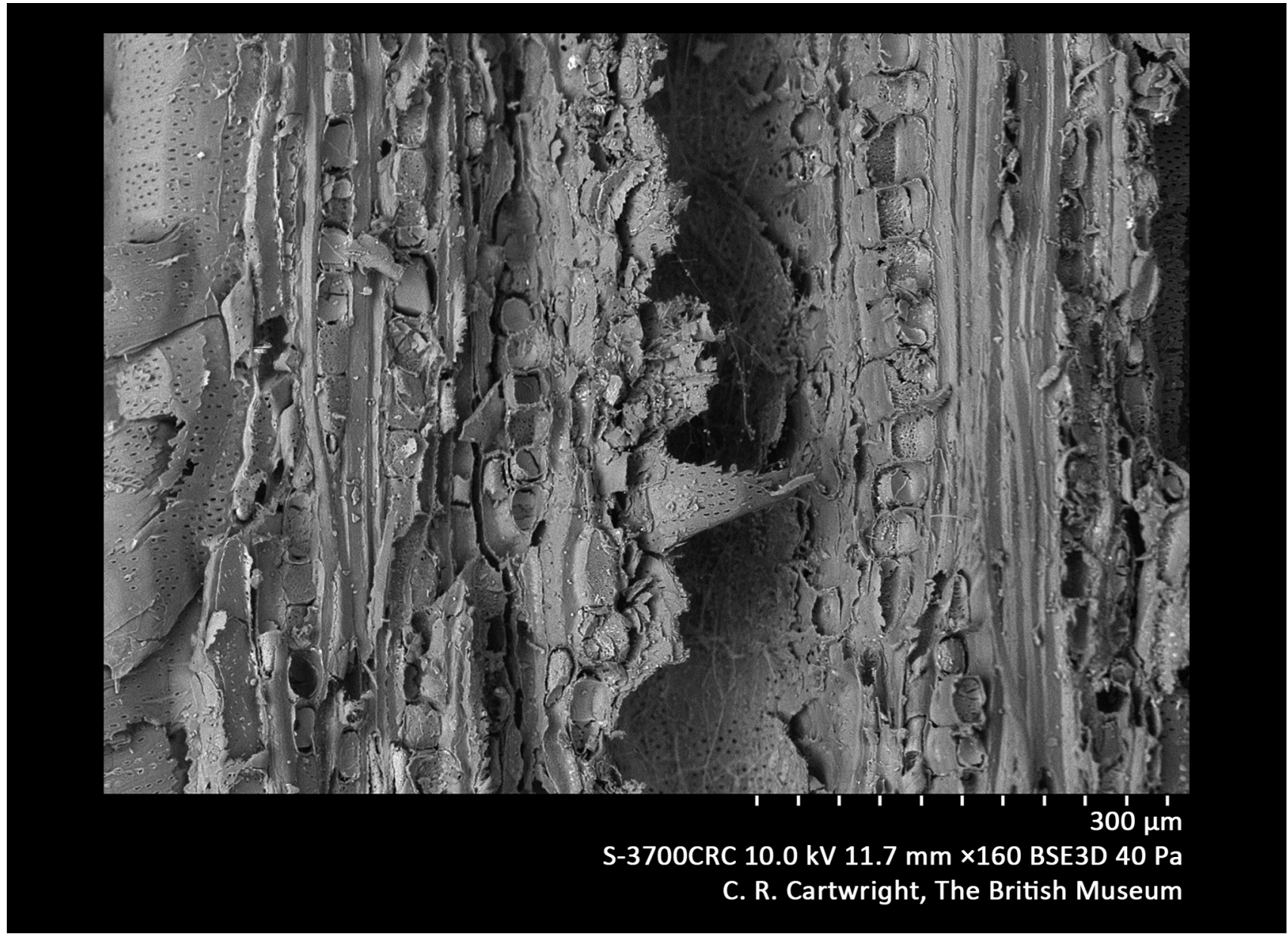

Figure 11. Scanning electron micrograph of a tangential longitudinal section of Ziziphus spina-christi (sidr) wood. Electron micrograph by C. R. Cartwright, The British Museum.

\section{Radiocarbon dating}

Radiocarbon dating was employed to date the boat. As the boat is made from at least 22 separate pieces (including figures and fittings, but excluding oars and at least half a dozen of dowels used in hull construction), multiple different pieces of wood were selected for dating. The wood samples for radiocarbon dating were taken from six separate pieces and eight radiocarbon results were obtained from three laboratories (Table 1). Before discussing the results, it must be remembered that radiocarbon dating provides an age for the timber, not necessarily an age for the construction of the model, although the timber ages do provide a maximum age for the model's construction.

The date for the lower-middle part of port of the hull is the youngest (1545 BC) while the date for the deck (central block of timber) is the second youngest (2087 BC). All remaining six dates, obtained for ram's head, prow, human figure and jackal, cluster within the 24th century BC (range: 2400-2305), mostly the late Fifth and Sixth Dynasty (2500 $2350 \mathrm{BC}$ and $2350-2200 \mathrm{BC}$ ).

A discord between dates should be noted; the dates for hull are younger while the dates for the "fittings" are not only older but also closer to each other. Six dates for

Table 1. Summary of radiocarbon dates (all on wood) extracted from reports referenced in the first column. Figures in parentheses are calculated by CalPal - Cologne Radiocarbon Calibration \& Paleoclimate Research Package (CalPal, 2007).

\begin{tabular}{ccccrrrr}
\hline lab ID & sample ID & D14C & F14C\% & $\begin{array}{c}\text { radiocarbon } \\
\text { date BP }\end{array}$ & $\begin{array}{r}\text { calibrated } \\
\text { date BP }\end{array}$ & $\begin{array}{r}\text { calibrated } \\
\text { range BP }\end{array}$ & $\begin{array}{c}\text { calibrated } \\
\text { date BC }\end{array}$ \\
\hline Wk-46193 & hull & $-333.5 \pm 1.3 \%$ & $66.7 \pm 0.1 \%$ & $3259 \pm 15$ & $3440(3495 \pm 33)$ & $3461-3528$ & $(1545 \pm 33)$ \\
Wk-46390 & deck & $-368.3 \pm 1.2 \%$ & $63.2 \pm 0.1 \%$ & $3690 \pm 15$ & $3970(4037 \pm 37)$ & $3999-4074$ & $(2087 \pm 37)$ \\
Wk-46190 & prow & $-381.7 \pm 1.1 \%$ o & $61.8 \pm 0.1 \%$ & $3862 \pm 15$ & $4230(4313 \pm 53)$ & $4259-4366$ & $(2363 \pm 53)$ \\
Wk-45421 & ram's head & $-382.9 \pm 1.2 \%$ o & $61.7 \pm 0.1 \%$ & $3878 \pm 16$ & $4240(4333 \pm 53)$ & $4182-4327$ & $2290(2383 \pm 53)$ \\
OxA-36007 ram's head & not available & not available & $3833 \pm 32$ & $4255(4255 \pm 72)$ & $4182-4327$ & $2199(2305 \pm 72)$ \\
OZY-645 & ram's head & not available & not available & $3902 \pm 25$ & $(4350 \pm 48)$ & $4302-4398$ & $2398(2400 \pm 50)$ \\
Wk-46192 & figure & $-381.6 \pm 1.1 \% 0$ & $61.8 \pm 0.1 \%$ & $3860 \pm 15$ & $4180(4308 \pm 50)$ & $4257-4358$ & $(2358 \pm 50)$ \\
Wk-46191 & jackal & $-379.0 \pm 1.2 \%$ & $62.1 \pm 0.1 \%$ & $3828 \pm 15$ & $4150(4215 \pm 33)$ & $4181-4248$ & $(2265 \pm 33)$ \\
\hline
\end{tabular}


"fittings" confirm each other, making them fairly reliable. The two younger dates are un-corroborated and must be treated with caution; they may indicate younger timber but equally may be a product of contamination or repair at a later point in time. It would be prudent to accept these dates as indicative, but uncertain. If we accept that radiocarbon age and calibrated dates are essentially an approximation of the calendar chronology, we can surmise that all dates collectively gravitate towards the late 3 rd millennium $\mathrm{BC}$, possibly including the First Intermediate Period (2200-2140 BC).

If taken at face value these results indicate the origin of the boat or some of its parts before the Middle Kingdom, just on a crest of decline of the Old Kingdom and cultural transformation rooted in the First Intermediate Period or somewhere between the end of the Old Kingdom and the Twelfth Dynasty (c. 2350-1850 BC-EschenbrennerDiemer, 2018:101).

\section{Discussion}

The evidence presented in this study needs to be placed in context; particularly for the implication of radiocarbon dates, availability of ancient timber, and the hypothesis of modern forgery.

Radiocarbon dates indicate the age of the timber. The material could have been used any time later by an artisan. How much later is a crucial question which cannot be precisely and conclusively answered. In theory, the boat could have been made between the 24th century BC and the 19th century of the Common Era. However, it is rather unlikely that a model such as this would be produced in the two past millennia when Egypt came under the influence of Hellenic, Roman, Christian and Islamic civilizations, and when knowledge and practice of ancient customs was largely abandoned and forgotten. In this long period of time there was lack of demand, incentive and most likely cultural competence for such craftwork to appear. The circumstances changed in the late 18th and the 19th centuries when knowledge of ancient Egyptian culture began rapidly expanding and, importantly, official and clandestine international markets for its artefacts became profitable and vigorous (Shaw, 2004; Romer, 2017). Effectively, the model could have been made in antiquity (BC), or in the 18-19th centuries of the Common Era.

If the model was made in antiquity, between the 24th and 16 th century $\mathrm{BC}$, as the radiocarbon dates suggest, it is not possible to pinpoint precisely the time of its origin. The distribution of dates is opened to multiple hypotheses. They include making, re-making, reassembling or refurbishing the boat from the combination of older and younger components. Furthermore, the two youngest dates may result from contamination as they are unconfirmed by other samples and are inconsistent with all other dates. It is noteworthy that among these samples which made up $27 \%$ of the timber pieces, not a single sample produced a modern date.

We must explain the discord between radiocarbon dates and the period in which the models of funerary boats are present, c. the mid-20th to 19th century BC (EschenbrennerDiemer, 2018:101; and pers. comm. 14 April 2021). Even the stylistically unusual AM E60381 model would be more likely associated with this period of radical cultural changes (the 2nd-half reign of Senusret I through to Senusret III). However, most dates for wood are from 23-24 century BC (one is significantly younger-16 century BC - an early stage of the New Kingdom). We can offer two hypotheses to account for the discord between the dates and expected chronological context. First, the six dates for 23-24 century $\mathrm{BC}$ could indicate yet unknown tradition of funerary boat models, emerging much earlier than usually asserted. While specific well-documented examples of such models are absent in time predating the 11-12 dynasties, the variety of all models were "in large part already present in the precursor group of the 4/5 dyn[asty] and post 6 dyn[asty] period" (Tooly, 1989:14). Secondly, the boat model in its current form was possibly assembled using and recombining older and younger parts in a process of maintenance, repairs, or remaking. This would be compatible with the numerous cases observed by Merriman (2011), suggesting that such practice was common rather than unusual. Some refurbishment or repair is a likely scenario and would account for the probable second selective repainting of the canopy with black paint. We think it is highly credible that at least some parts of the model originated in the late $3 \mathrm{rd}$ millennium BC, but it does not mean that final product in its present form is of the same age. Equally the last time the boat was re-assembled does not equate with the period of its origin. The model appears to be a product of chain of episodes of repair and reworking, stretched in time which, on balance, mostly occurred in antiquity.

The use of ancient timber in hypothetical 19th century replicas must be addressed. Wood, generally well preserved in Egypt, was on occasions stored for future use, but usually extensively recycled, reused and sometimes even obtained by robbery and theft (Creasman, 2013; Mark, 2012). By implication, to find the four thousand years old timber would be difficult in modern times, unless reused from ancient artefacts.

Broken and incomplete objects were reused in the modern era, especially coffins as they provided bigger pieces for small craftwork. However, reused wood tends to be inferior in preservation and does not always provide the type of timber required. Well-preserved old wood and the deliberate selection of species in the AM E60381 model suggest it was not made from recycled timber, rendering less credible a 19th century-origin for the model.

Furthermore, the ancient paint pigments combined with ancient methods of construction and iconographic accuracy suggest an ancient origin for the model. In addition, the boat has been damaged (broken and lost horns, broken ram's head, split gunwale) and its painted decoration is extensively degraded, providing further support for a premodern manufacturing date.

If this boat were a 19th century pastiche, it would be an outstanding piece of deception, where the hypothetical forger left not a trace of evidence of its modern origin. The only evidence of 19th century work consists of repairs of the model with small metal nails. This repair work was done explicitly, somewhat crudely, without an attempt to imitate ancient practice and hence without the intention to deceive.

Constructing the model from several pieces of wood and joining them with dowels is characteristic of ancient Egyptian woodwork. Use of harder wood for dowel(s) reveals a small but interesting detail of technical competency. Depiction of mourners and lion-like legs of the bier reveals 
close familiarity with iconography and its symbolism. Painted details such as belt or a string holding the skirts of some human figures or a tiny carving of a falcon head on the oar's handle demonstrate attention to details that ceremonial or sacred objects would require, even if they add little to the overall visual appeal of the entire model.

All materials, dates obtained so far, the craftwork technique, style and iconographic elements are compatible with Egyptian antiquity. In addition, a combination of funerary and sacred bark elements would fit broadly into the period of transition from the Old Kingdom to the early Middle Kingdom, with its spiritual and political focus on Thebes and Amun, and possibly with a transitory stage when funerary boat models evolved as a separate, distinct category of funerary paraphernalia (Reisner, 1913:XXII).

\section{Conclusions}

The AM E60381 boat is one of many unprovenanced models of ancient Egyptian watercrafts. Some of these models held in major museums, such as the Museum of Egyptian Antiquities in Cairo, the Metropolitan Museum in New York or The British Museum in London, warrant closer scrutiny because they often provide essential references for students of antiquity (cf. Lowenthal, 1992; Lilyquist, 2003; Boange, 2012; Eschenbrenner-Diemer, 2016, 2018). The boat model which is the subject of this paper has a legacy of doubt concerning its authenticity. It came from an untrustworthy dealer and it has an unusual design. Under this assumption of forgery, this boat remained un-examined for over a century.

This study presents, for the first time, a set of technical analyses and an exploration of the historical context in which a craft of such an atypical design could have been conceived. While no single analytical result provides definite conformation of the boat's origin and history, collectively they provide a cohesive body of evidence.

Our analyses show that the AM E60381 boat is compatible with ancient Egyptian practices in design and iconography and the application of gesso and paint. In addition, the construction methods along with the types of wood and pigment used indicate antiquity. Furthermore, the boat's preservation condition, with some peripheral damage and decay, imply its "existence" for a considerable period of time. This chronological length is reinforced by eight radiocarbon dates which show the oldest wood is from the late 3rd millennium $\mathrm{BC}$.

The only evidence of modern work consists of a 19th century repair of the model with small metal nails. This was done without an attempt to imitate ancient practice and hence suggests modern repair rather than modern origin.

The most probable explanation is that the boat was constructed roughly at the time the wood became available (cut, transported, cured etc) in a period and culture that possessed all iconographic, narrative and technical knowledge, competence and confidence to conceive such a symbolic object.

In summary, we conclude that the modern hypothesis of origin cannot be substantiated in the light of evidence examined in this study. The ancient origin of the boat is the most likely explanation. By accepting the ancient origin of the boat as the most convincing proposition we are gaining some insights into its history but also confronting new questions which cannot presently be answered. The distribution of radiocarbon dates, combined with the episodes of repainting may suggest the boat was made, later refurbished or re-assembled, from some older and younger elements, probably somewhere between the 24th and 16 th century BC. Relatively good preservation of wood indicates the boat was kept most of the time in favourable conditions, possibly a dark and sealed burial chamber.

Our research is provisional; therefore we advocate further exploration of the boat model's identity and history. Rapidlyadvancing analytical methods of research offer new and exciting possibilities. We believe the identity of the model could be further examined by conducting more detailed and systematic X-ray imaging. Construction methods including some aspects of the sequence of joining separate pieces together could inform us more about the construction, likelihood of tools and period of construction. High resolution photography could help to reconstruct original painting patterns and reveal separate episodes of painting when subsequent paint applications overlay previous, older paint. Also, mineral (e.g. pigments) and organic (e.g. adhesive) samples could potentially be analysed for their geographical origin. We hope there will be an opportunity to pursue these questions in the future.

ACKNOWLEDGEMENTS. This research was generously sponsored by Jenny Crivelli, who supports the Funerary Boat through the Australian Museum Foundation's Treasures Circle program and in addition showed keen interest in research progress and its results. Several specialists and colleagues supported us or contributed directly to this research and we are grateful for their involvement. Kim McKay and Dr Jenny Newell (Australian Museum) facilitated our research. Dr John Taylor (The British Museum) offered us important comments that clarified our understanding of the arguments in favour of modern replica hypothesis. Dr James Fraser (Nicholson Museum, University of Sydney) provided critical comments, encouragement and practical suggestions. Dr Fiona Petchey (University of Waikato) helped to analyse and discuss radiocarbon dates and their implications. Dr Val Attenbrow (Australian Museum) helped with analysis and presentation of radiocarbon dates. Dr Vladimir Levchenko (ANSTO) procured one radiocarbon date as ANSTO in-kind contribution to our project. Dr Elizabeth Carter (University of Sydney) analysed some mineral samples (Raman Spectroscopy). Dr Paula Dredge (Art Gallery of NSW) made X-ray images. Dr Gersande Eschenbrenner-Diemer and two anonymous academics reviewed the draft, offering helpful suggestions. Anina Hainsworth and Adria Castellucci, Librarians (Australian Museum) assisted in accessing publications. Peter Dadswell, Penny Zylstra and Susan Myatt (Australian Museum) helped with proofreading.

Dr Caroline R. Cartwright (The British Museum) identified wood samples, provided their images and explained the context and significance of use of different wood species. We regret that for the combination of technical and administrative reasons which disrupted her involvement in preparation of this paper in the early part of 2020 she was unable (on her own request) to join us as coauthor. We highly value and are grateful for her contribution and her electron micrographs (Figs 9-11). 


\section{Endnotes}

1 The Australian Museum holds 75 Egyptian artefacts acquired by Wunderlich from Ratzkowski; c. 48 are crude replicas including forgeries and plaster casts; some objects are deemed as authentic via subsequent assessments and studies. Flinders Petrie examined this collection via photos in 1914-15 (excluding boat model), asserting it contained "spurious specimens." Australian Museum Archives E34/1914, P7/1915, AN92/20.

2 Since the model was placed at the Museum in 1913, it was disassembled on some occasions; no systematic photographic documentation was made; it appears Merriman (2011: 437) was provided a photo of an incompletely assembled model by the Museum of Ancient Cultures, Macquarie University, on which she based her assessment.

3 Dates for dynasties are quoted from Romer, 2012:524 and Romer, 2017:524-525.

4 According to Rich (2013:77) the hull's length to width ratio broadly indicates a boat's function, where cargo and travelling boats are 1:3, longer and narrower, war and racing vessels are 1:5 and funerary boats are 1:4.

$5 \quad 1$ to the 9 th dynasty; 2 to the 10th dynasty; and 2 undetermined.

6 Southern Asasif, tomb of Meketre (TT 280, MMA 1101), recovered via excavation by the Egyptian Expedition of the Metropolitan Museum of Art in 1920 (Yamamoto, 2015:254-255).

https://www.metmuseum.org/art/collection/search/577298

7 This was the reign of Senwosret II (ruled 1897-1878 BC), Senwosret III (ruled 1878-1839 BC) and Amenemhot III (ruled 1860-1814 BC).

8 Nebhepetre Mentuhotep II, considered the founder of the Middle Kingdom, reigned for over 50 years, c. 2051-2000 BC (Grajetzki, 2015:307).

9 Ram's head with sun disk would indicate Amun-Re as depicted on Amun's barque.

10 Other sources quote length as $86.4 \mathrm{~cm}$ (Glenville 1972:6264; Merriman 2011:203).

11 At times the boat was not assembled correctly as the mummy with bier is not pegged to the deck but free-standing and the jackal could be turned to face the back or front. Both mummy's head and jackal should be facing the prow, which, we believe, is defined by a slightly shorter ram's head.

12 It is recognized that Egyptian blue pigment could transform into green as a result of decay (Pagés-Camagna \& Colinart, 2003).

13 Ficus sycomorus, sycomore fig, belongs to the Moraceae family and is unrelated to the true sycamore tree, Acer pseudoplatanus of the Sapindaceae family, distributed across central Europe (Cartwright, 2019).

14 Wood kept in relatively sterile and stable conditions such as burial chamber, sealed from outside influence, dark, with comparatively minimal variation in temperature and humidity, can be preserved for a long time (Abdelraheem et al., 2018:2; also Cartwright \& Taylor, 2015). In contrast, recycled wood, kept for some period(s) of time exposed to the elements or less favourable conditions, might show more advanced deterioration.

\section{References}

Abdelraheem, A., E. Abdelraheem, Z. Al-Muheisen, F. Villeneuve, and F. A. El-Oqlah. 2018. The conservation of a wooden nabataean coffin box from Jordan-application of nondestructive ultrasonic technique. Wood Research 63(1): 1-14 http://www.woodresearch.sk/wr/201801/01.pdf

Abdrabou, A., M. Abdallah, and M. Abd el Kader. 2015. Analytical study and conservation process of a painted wooden GrecoRoman coffin. International Journal of Conservation Science 6(4): 673-586.

Abubakr, A. M., and A. Y. Mustafa. 1971. The funerary boat of Khufu. Beiträge zur ägyptischen Bauforschung und Altertumskunde 12: 1-16.

Arnold, D. 2015a. Statues in their Settings: Encountering the Divine. In Ancient Egypt Transformed: The Middle Kingdom, ed. A. Oppenheim, D. Arnold, D Arnold, and K. Yamamoto, pp. 17-22. New York: The Metropolitan Museum of Art.

Arnold, D. 2015b. Model sailing boat transporting a mummy. In Ancient Egypt Transformed: The Middle Kingdom, ed. A. Oppenheim, D. Arnold, D. Arnold, and K. Yamamoto, pp. 222-223. New York: The Metropolitan Museum of Art.

Arnold, D., and D. Arnold. 2015. A new start from the south: Thebes during the Eleventh Dynasty. In Ancient Egypt Transformed: The Middle Kingdom, ed. A. Oppenheim, D. Arnold, D. Arnold, and K. Yamamoto, pp. 38-53. New York: The Metropolitan Museum of Art.

Amoros V. Asensi, G. Eschenbrenner-Diemer, C. Lavier, and S. Pages-Camagna. 2012. Study and identification of ancient Egyptian polychrome woods: the funerary models of the Museum of Fine Arts at Lyon (France). Hathor-Studies of Egyptology 1: 11-25.

Australian Museum. 2017.200 Treasures of the Australian Museum. Sydney: Australian Museum.

Berger, M. 1982. The petroglyphs at Locality 61. In The Predynastic of Hierakonpolis. An Interim Report. (ESA 1), ed. M. A. Hoffman, pp. 61-65. Cairo and Illinois: Alden Press.

Berger, M. 1992. Predynastic animal-headed boats from Hierakonpolis and southern Egypt. In The Followers of Horus. Studies Dedicated to Michael Allen Hoffman, ed. R. Friedman and B. Adams, pp. 107-120. Oxford: Oxbow.

Blanchette, R. A., John-Erich Haight, R. J. Koestler, P. Hatchfield, and D. Arnold. 1994. Assessment of deterioration in archaeological wood from ancient Egypt. Journal of the American Institute for Conservation 33(1): 55. https://doi.org/10.1179/019713694806066428

British Museum EA9505 Collection Online [n.d.] [Accessed 21 September 2020].

https://www.britishmuseum.org/collection/object/Y_EA9505

Boange, S. 2012. To be or not to be? An in depth object study and discussion of authenticity of a Four Sons of Horus amulethoused in the Museum of Ancient Cultures at Macquarie University, North Ryde. Unpublished Honours Thesis: Macquarie University.

Brier B., and H. Hobbs. 2008. Daily Life of the Ancient Egyptians. Westport and London: Greenwood Press.

Callandar, G. 2000. The Middle Kingdom Renaissance. In The Oxford History of Ancient Egypt, ed. I. Shaw, pp. 148-183. Oxford: Oxford University Press.

CalPal, Online. 2007. Cologne Radiocarbon Calibration \& Paleoclimate Research Package. http://www.calpal-online.de/index.html

Cartwright, C. R. 2004. Cedrus libani under the microscope; the anatomy of modern and ancient Cedar of Lebanon wood. In Decade. A Decade of Archaeology and History in the Lebanon, ed. C. Doumet-Serhal, pp. 472-479. Beirut: The Lebanese Friends of the National Museum. 
Cartwright, C. R. 2013. Appendix 7: Wood Identification. In The Gurob Ship-Cart Model and its Mediterranean Context, ed. S. Wachsmann. Texas: A \& M University Press.

Cartwright, C. R. 2015. The principles, procedures and pitfalls in identifying archaeological and historical wood samples. Annals of Botany 116 (1): 1-13. https://doi.org/10.1093/aob/mcv056

Cartwright, C. R. 2016. Wood in ancient Egypt: choosing wood for coffins. In Death on the Nile. Uncovering the Afterlife of Ancient Egypt, ed. J. Dawson and H. Strudwick, pp. 78-87, 251. London: The Fitzwilliam Museum, Cambridge in association with D. Giles Limited.

Cartwright, C. R. 2017. Unpublished report on wood identification for model boat E60381 from the Australian Museum collection. Australian Museum Archives TRIM $17 / 1572$.

Cartwright, C. R. 2019. Identifying ancient Egyptian coffin woods from the Fitzwilliam Museum, Cambridge using scanning electron microscopy. In Ancient Egyptian Coffins. Past. Present. Future, ed. H. Strudwick and J. Dawson, pp. 1-12. Oxford: Oxbow Books.

https://doi.org/10.2307/j.ctvh9w0cw.5

Cartwright, C. R., and J. H. Taylor. 2015. Ancient Egyptian funerary food: new insights. British Museum Technical Research Bulletin 9: 97-105.

Creasman, P. P. 2005. The Cairo Dahshur Boats. MA Thesis, Texas A \& M University.

Creasman, P. P. 2010. Overland boat transportation during the pharaonic period: archaeology and iconography (Laboratory of Tree-Ring Research, University of Arizona) and Noreen Doyle (Institute of Maritime Research and Discovery). Journal of Ancient Egyptian Interconnections 2,3: 14-30.

Creasman, P. P. 2013. Ship timber and the reuse of wood in Ancient Egypt. Journal of Egyptian History 6: 152-176.

https://doi.org/10.1163/18741665-12340007

Creasman, P. P., and N. Doyle. 2015. From Pit to Procession: The diminution of ritual boats and the development of royal burial practices in pharaonic Egypt. Studienzur Altägyptischen Kultur 44: 83-101.

Dürring, N. 1995. Materialienzum Schiffbauim Alten Ägypten. Berlin: Berlin: Achet-Verlag.

Eldamaty, M., and M. Trad, eds. 2002. Egyptian Museum Collections around the World. Studies for the Centennial of the Egyptian Museum. Cairo: The Supreme Council of Antiquities Cairo.

Eschenbrenner-Diemer, G. 2013. Les «modèles» égyptiens en bois. Matériau, fabrication, diffusion, de la fin de l'Ancien à la fin du Moyen Empire (env. 2350-1630 av. J.-C). Unpublished $\mathrm{PhD}$ thesis.

Eschenbrenner-Diemer, G., and A. Portai. 2016. Un nouveau regard sur des modèles de bateaux égyptiens au musée du Louvre. Revue des Musées de France 2016(1): 18-29.

Eschenbrenner-Diemer, G. 2017. From the workshop to the grave: the case of funerary wooden models (end of VIth dynasty-XIIth dynasty). In Proceedings of the International Conference Company of Images: Modelling the Ancient Egyptian Imaginary World of the Middle Bronze Age (2000-1500 BC), 18-20 September 2014, University College London. Orientalia Lovaniensia Analecta 262: 133-192.

Eschenbrenner-Diemer, G. 2018. The Petrie Museum's Collection of funerary wooden models: investigating chronology and provenances. Archaeology International 21: 101-108. https://doi.org/10.5334/ai-378

Fiechter J. J., 2009. Egyptian Fakes Masterpieces that Duped the Art World and the Experts who Uncovered Them. Paris: Flammarion.

Freed, R. E., L. M. Berman, D. M. Doxey, and N. Picardo. 2009. The Secrets of Tomb 10A: Egypt 2000 BC. Boston: Museum of Fine Arts.
Giménez, J. 2015. Egyptian Blue and/or atacamite in an ancient Egyptian coffin. International Journal of Conservation Science 6(4): 747-749.

Glanville, S. R. K. 1972. Catalogue of Egyptian Antiquities in the British Museum II: Wooden Model Boats. London: British Museum Press.

Grajetzki, W. 2006. The Middle Kingdom of Ancient Egypt: History, Archaeology and Society. Bristol: Bristol Classical Press.

Grajetzki, W. 2015. Middle Kingdom history: an overview. In Ancient Egypt Transformed: The Middle Kingdom, ed. A. Oppenheim, D. Arnold, D Arnold, and K. Yamamoto, pp. 306-310. New York: The Metropolitan Museum of Art.

Jenkins, N. 1980. The Boat Beneath the Pyramid: King Cheops Royal Ship. New York: Holt, Rinehart and Winston. http://www.gizapyramids.org/static/pdf\%20library/jenkins_boat.pdf

Jones, D. 1990. Model Boats from the Tomb of Tut'ankhamun. Oxford: Griffith Institute.

Kemp, B. J. 2006. Ancient Egypt: Anatomy of Civilisation. London and New York: Routledge. https://doi.org/10.4324/9780203468821

Lane Fox [Pitt-Rivers], A. H. 1875. On early modes of navigation. Journal of the Anthropological Institute of Great Britain and Ireland 14: 399-437. https://doi.org/10.2307/2840984

Lilyquist, C. 2003. The Tomb of the Three Foreign Wives of Thutmosis III. New York: The Metropolitan Museum of Art.

Lipke, P. 1984. The Royal Ships of Cheops: a retrospective account of the discovery, restoration and reconstruction. Based on interviews with Hag Ahmed Youssef Moustafa. BAR International Series 225. Greenwich: National Maritime Museum.

Lowenthal, D. 1992. Counterfeit art: authentic fakes. International Journal of Cultural Property 1: 79-104. https://doi.org/10.1017/S0940739192000067

Mark, S. 2009. The construction of the Khufu I Vessel (c. 2566 BC): a re-evaluation. International Journal of Nautical Archaeology 38.1: $133-152$. https://doi.org/10.1111/j.1095-9270.2008.00212.x

Mark, S. 2012. The Abydos BG 10 Boat and implications for standardization, innovation, and timber conservation in early dynastic boat-building. The Journal of Egyptian Archaeology 98(1): 107-126. https://doi.org/10.1177/030751331209800107

McGrail, S. 2001. Boats of the World: From the Stone Age to Medieval Times. Oxford: Oxford University Press.

Merriman, A. M. 2011. Egyptian Watercraft Models from the Predynastic to Third Intermediate Periods. British Archaeological Reports International Series 2263 Oxford: BAR. https://doi.org/10.30861/9781407308340

Murnane, W. J. 1979. The Bark of Amun on the Third Pylon at Karnak. Journal of the American Research Center in Egypt 16: 11-27. https://doi.org/10.2307/40000315

Newman, R., and M. Serpico. 2000. Adhesives and binders. In Ancient Egyptian Materials and Technology, ed. P. T. Nicholson, and I. Shaw, pp. 476-492. Cambridge: Cambridge University Press.

North, A. 2015. Examination of Wooden Tomb Models. [dated 4 Dec 2015, accessed 17 Mar 2019]

https://www. penn. museum/sites/artifactlab/2015/12/04

examination-of-wooden-tomb-models/

Oppenheim, A. 2015. Introduction: what was the Middle Kingdom? In Ancient Egypt Transformed: The Middle Kingdom, ed. A. Oppenheim, D. Arnold, D. Arnold, and K. Yamamoto, pp. 6. New York: The Metropolitan Museum of Art.

Pagés-Camagna S., and S. Colinart. 2003. The Egyptian green pigment: its manufacturing process and links to Egyptian blue. Archaeometry 45(4): 637-658. https://doi.org/10.1046/j.1475-4754.2003.00134.x 
Petrie, W. M. F. 1933. Egyptian Shipping. Ancient Egypt and the East I \& II: 1-14, 64-75 (March and June, 1933).

Petrie, W. M. F., and G. Brunton. 1924. Sediment, I. BSAE 34. London: British School of Egyptian Archaeology.

Quirke, S. 2015. Understanding death: a journey between worlds. In Ancient Egypt Transformed: The Middle Kingdom, ed. A. Oppenheim, D. Arnold, D. Arnold, and K. Yamamoto, pp. 218-249. New York: The Metropolitan Museum of Art.

Redford, D. B. 2002. The Ancient Gods Speak: A Guide to Egyptian Religion. Oxford and New York: Oxford University Press.

Reisner, G. 1913. Models of Ships and Boats. Catalogue Général des Antiquités Egyptiennes du Musée du Caire. Cairo, LeCaire: l'Institut Français D'archéologie Orientale. https://archive.org/details/modelsofshipsboa00reis/page/50

Rich, S. 2013. Ship Timber as Symbol? Dendro-provenancing \& Contextualizing Ancient Cedar Ship Remains from the East Mediterranean / Near East. PhD thesis. Katholieke Universiteit Leuven.

Romer, J. 2012. A History of Ancient Egypt: From the First Farmers to the Great Pyramid. New York: Thomas Dunne Books.

Romer, J. 2017. A History of Ancient Egypt, Volume 2: From the Great Pyramid to the Fall of the Middle Kingdom. Penguin Books.

Shaw, I. 2004. Ancient Egypt: A very Short Introduction. Oxford and New York: Oxford University Press. https://doi.org/10.1093/actrade/9780192854193.001.0001

Silverman, D. P., W. K. Simpson, and J. Wegner. 2009. Archaism and innovation: defining the cultural expression of Egypt's Middle Kingdom. In Archaism and Innovation: Studies in the Culture of Middle Kingdom Egypt, ed. D. P. Silverman, W. K. Simpson, J. Wegner, pp. IX-XIII. New Haven and Philadelphia: Yale University and University of Pennsylvania Museum of Archaeology and Anthropology.

SMH. 1913. Sydney Morning Herald (22 November 1913), p. 20.
Stevenson, A. 2019. Scattered Finds: Archaeology, Egyptology and Museums. London: UCL Press.

https://doi.org/10.2307/j.ctv550cxt

Strudwick, N., T. G. H. James, and E. R. Russmann. 2006. Temples and tombs: treasures of Egyptian art from the British Museum, pp. 84-85. Seattle and Londres: American Federation of Arts and University of Washington Press.

Sullivan, E. A. 2012. Visualising the size and movement of the portable festival barks at Karnak temple. British Museum Studies in Ancient Egypt and Sudan 19: 1-37.

Tooley, A. M. J. 1989. Middle Kingdom Burial Customs. A Study of Wooden Models and Related Materials. Unpublished thesis of the University of Liverpool.

Ward, C. A. 2000. Sacred and Secular: Ancient Egyptian Ships and Boats. Philadelphia: Archaeological Institute of America.

Wegner, J. 2009. The tomb of Senwosret III at Abydos: considerations on the origins and development of the Royal Amduat-Tomb. In Archaism and Innovation: Studies in the Culture of Middle Kingdom Egypt, ed. D. P. Silverman, W. K. Simpson, and J. Wegner, pp. 103-168. New Haven and Philadelphia: Yale University and University of Pennsylvania Museum of Archaeology and Anthropology.

Wegner, J. 2017. A Royal Boat Burial and Watercraft Tableau of Egypt's 12th Dynasty (c. $1850 \mathrm{BCE}$ ) at South Abydos. The International Journal of Nautical Archeaology 46.1: 5-30. https://doi.org/10.1111/1095-9270.12203

Winlock, H. E. 1955. Models of daily life in Ancient Egypt: from the tomb of Meket-Re' at Thebes. Cambridge: Published for the Metropolitan Museum of Art by Harvard University Press.

Yamamoto, K. 2015. Model sailboat and paddling boat. In Ancient Egypt Transformed: The Middle Kingdom, ed. A. Oppenheim, D. Arnold, D. Arnold, and K. Yamamoto, pp. 254-255. New York: The Metropolitan Museum of Art. 
Plate 1

Funerary boat model (Australian Museum E60381), portboard (left side).

Photo by Stuart Humphreys (Australian Museum, Sydney). 


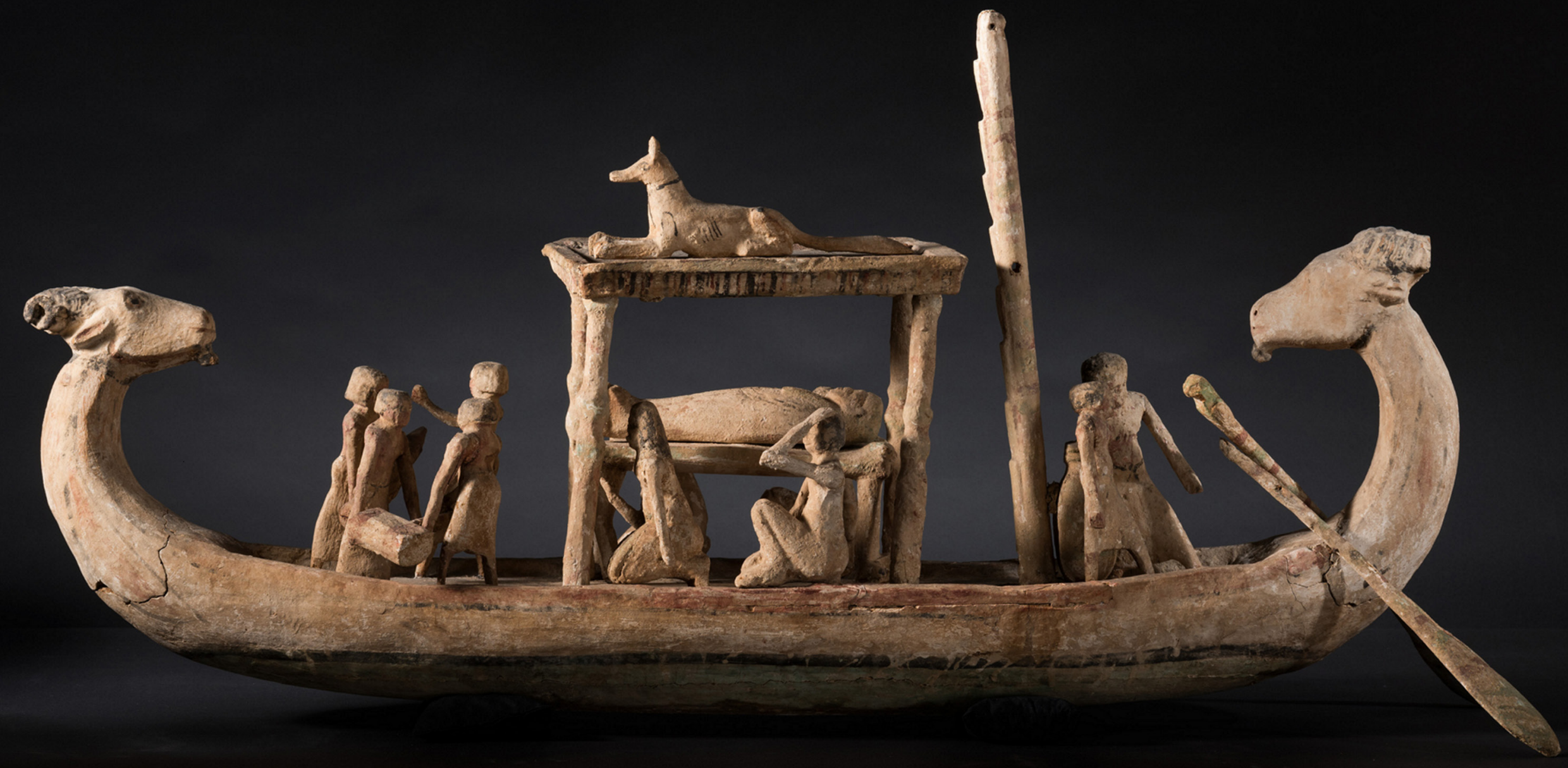

